\title{
Modeling Human Neurological and Neurodegenerative Diseases: From Induced Pluripotent Stem Cells to Neuronal Differentiation and Its Applications in Neurotrauma
}

OPEN ACCESS

Edited by:

Ildikó Rácz,

University of Bonn, Germany

Reviewed by:

Daniele Bottai,

University of Milan, Italy

Chiara Verpelli,

National Research Council (CNR), Italy

Christian Gonzalez-Billault,

University of Chile, Chile

*Correspondence:

Wassim Abou-Kheir

wa12@aub.edu.lb

${ }^{\dagger}$ These authors have contributed equally to this work.

Received: 16 November 2016 Accepted: 13 February 2017

Published: 28 February 2017

Citation:

Bahmad H, Hadadeh O, Chamaa F, Cheaito K, Darwish B, Makkawi A-K and Abou-Kheir W (2017) Modeling

Human Neurological and Neurodegenerative Diseases: From Induced Pluripotent Stem Cells to

Neuronal Differentiation and Its Applications in Neurotrauma.

Front. Mol. Neurosci. 10:50

doi: 10.3389/fnmol.2017.00050

\section{Hisham Bahmad ${ }^{\dagger}$, Ola Hadadeh ${ }^{\dagger}$, Farah Chamaa, Katia Cheaito, Batoul Darwish, Ahmad-Kareem Makkawi and Wassim Abou-Kheir*}

Department of Anatomy, Cell Biology and Physiological Sciences, Faculty of Medicine, American University of Beirut, Beirut, Lebanon

With the help of several inducing factors, somatic cells can be reprogrammed to become induced pluripotent stem cell (iPSCs) lines. The success is in obtaining iPSCs almost identical to embryonic stem cells (ESCs), therefore various approaches have been tested and ultimately several ones have succeeded. The importance of these cells is in how they serve as models to unveil the molecular pathways and mechanisms underlying several human diseases, and also in its potential roles in the development of regenerative medicine. They further aid in the development of regenerative medicine, autologous cell therapy and drug or toxicity screening. Here, we provide a comprehensive overview of the recent development in the field of iPSCs research, specifically for modeling human neurological and neurodegenerative diseases, and its applications in neurotrauma. These are mainly characterized by progressive functional or structural neuronal loss rendering them extremely challenging to manage. Many of these diseases, including Parkinson's disease (PD), Huntington's disease (HD), Amyotrophic lateral sclerosis (ALS) and Alzheimer's disease (AD) have been explored in vitro. The main purpose is to generate patient-specific iPS cell lines from the somatic cells that carry mutations or genetic instabilities for the aim of studying their differentiation potential and behavior. This new technology will pave the way for future development in the field of stem cell research anticipating its use in clinical settings and in regenerative medicine in order to treat various human diseases, including neurological and neurodegenerative diseases.

Keywords: induced pluripotent stem cells (iPSCs), neuronal differentiation, Parkinson's disease (PD), Huntington's disease (HD), Amyotrophic lateral sclerosis (ALS), Alzheimer's disease (AD), spinal cord injuries (SCI)

\section{INTRODUCTION}

Stem cell research is considered one of the most captivating areas of cell biology mainly due to the unique properties of stem cells and their potential use in cell-based therapies to treat a variety of diseases, including Parkinson's disease (PD), Alzheimer's diseases (AD), Diabetes Mellitus (DM), and many others (Correia et al., 2005; Pagliuca et al., 2014; Sproul, 2015). Given their unique regenerative abilities, these cells provide new potentials in the area of regenerative or reparative medicine. 
Embryonic stem cells (ESCs), which are derived from the inner cell mass (ICM) of blastocysts, are pluripotent cells that have the ability to proliferate indefinitely. But still they maintain their pluripotency with the capability to differentiate into cells of all three germ layers: ectoderm, mesoderm and endoderm (Evans and Kaufman, 1981; Martin, 1981). In addition, these cells serve as an internal repair system, limitlessly regenerating into either differentiated cell progeny or additional stem cells (Keller, 1995; Thomson et al., 1998). Since first isolated in 1998, human ESCs have featured high importance as a potential treatment of a variety of diseases like PD, spinal cord injury (SCI) and DM (Thomson et al., 1998). However, the extraction of ESCs raises sharp ethical controversies as they are derived from human embryos and their transplantation in patients may present serious risks with a possibility of rejection (Lo and Parham, 2009).

Alternative approaches to the derivation of ESCs from the ICM of pre-implanted embryos are now available and these tend to avoid ethical issues. Such methodologies directly generate pluripotent stem cell lines from differentiated adult somatic tissue and include nuclear transfer, cell fusion or direct reprogramming (Hochedlinger and Jaenisch, 2006). In 2006, a landmark discovery was published by the Yamanaka group at Kyoto University as they induced the expression of only four pluripotency-associated transcription factors, Oct3/4, Sox2, c-Myc, and Klf4 (OKSM), in mouse fibroblast cells resulting in the generation of ESC-like cells, called induced pluripotent stem cells (iPSCs). These cells are similar to the ESCs in their morphology, gene expression, proliferation and teratoma formation (Hochedlinger and Jaenisch, 2006; Takahashi and Yamanaka, 2006; Takahashi et al., 2007; Wernig et al., 2007; Hadadeh et al., 2012). These iPSCs are now widely used for various applications, such as autologous cell therapy, monogenic and multigenic diseases modeling, and as substrates for drug, toxicity, differentiation and therapeutic screens.

Reprogramming highly depends on the efficient delivery and the suitable expression of certain factors into specific cell types, under particular culture conditions and within a period of time. Although direct reprogramming is a simple technique, it differs depending on the cell type, species and delivery method. It is rather a slow and vulnerable process that may be affected by several factors that hinder the efficiency, reproducibility and the quality of the resulting iPSCs. To date, the most popular donor somatic cells are fibroblasts, being used in more than $80 \%$ of all reprogramming experiments published (González et al., 2011). Yet, other cell types have been used in reprogramming such as

\footnotetext{
Abbreviations: AD, Alzheimer's disease; ALS, Amyotrophic lateral sclerosis; $A \beta$, amyloid beta; BDNF, brain-derived neurotrophic factor; BMP, bone morphogenic protein; CRISPR, Clustered Regularly Interspaced Short Palindromic Repeats; DA, dopaminergic; DKK1, Dickkopf WNT signaling pathway inhibitor 1; DM, diabetes mellitus; EBs, embryoid bodies; ESCs, embryonic stem cells; GDNF, glial cell linederived neurotrophic factor; HD, Huntington's disease; HD-NSCs, Huntington's disease specific neural stem cells; hiPSCs, human induced pluripotent stem cells; iPSCs, induced pluripotent stem cells; ICM, inner cell mass; Lmx1a, LIM homeobox transcription factor 1a; mDA, midbrain dopaminergic; NSCs, neural stem cells; NPCs, neuroprogenitor cells; PD, Parkinson's disease; RA, retinoic acid; $\mathrm{SHH}$, sonic hedgehog; SOD1, superoxide dismutase 1 gene; SCI, spinal cord injury; TUJ1, class III- $\beta$-tubulin; VPA, valproic acid.
}

human primary keratinocytes, cord blood CD133+ cells, and peripheral blood mononuclear cells (Aasen et al., 2008; Giorgetti et al., 2009; Su et al., 2016).

A successful management of the outcome of somatic cell reprograming to iPSCs is related to both the reprograming technique and the type of cells that are used. Here, it is important to note that although fibroblasts are the most widely used cells for iPSCs generation, this does not necessarily mean that they represent the highest efficacy. In fact, since the first approach toward creating iPSCs was obtained from fibroblasts (Takahashi and Yamanaka, 2006), subsequent protocols tried to reproduce that process before other alternatives for fibroblasts were investigated. Fibroblasts are easy to cultivate in culture and much is known about these cells in research. An important characteristic of these cells that makes them great candidates is the low methylation levels of the promotor regions of OCT4 and NANOG that can be associated with the favorable reprogramming of the cells. Furthermore, fibroblasts can be easily obtained from patients through biopsy and are relatively inexpensive and widely commercially available by many companies. However, the fact that fibroblasts are highly proliferative poses few disadvantages as the non-programmed fibroblasts can have the opportunity to overgrow the existing reprogrammed cells and consume the growth factors in the media. This can usually be overcome by using a low passage not exceeding passage 5 in order to avoid accumulated genomic changes (Raab et al., 2014).

Reprogramming can be induced by the co-introduction of some genes that are expressed early during development, such as OCT4, SOX2, NANOG, UTF1, and SALL4, and which are implicated in the maintenance of the pluripotent potential of the ICM (Niwa, 2007; Zhao et al., 2008; Tsubooka et al., 2009). Supplementation with other genes such as c-MYC, KLF4, TERT, and SV4OLT can enhance cell proliferation in a direct or indirect manner (Park et al., 2008b). Additionally, microRNAs (miRNAs) have been implicated in pluripotency and reprogramming, such as the miR-290 cluster and miR-302 cluster miRNAs (Wang et al., 2008; Mallanna and Rizzino, 2010). On the other hand, there are several chemical compounds that have proven to enhance reprogramming in different cell types. Those compounds are known to alter DNA methylation or cause chromatin modifications and they include DNA methyltransferase inhibitor 5 -azacytidine or histone deacetylase (HDAC) inhibitors (such as hydroxamic acid (SAHA), trichostatin A (TSA), and valproic acid (VPA)) (Huangfu et al., 2008). The delivery of the OKSM transcription factors into mouse or human fibroblasts is achieved using different viral and non-viral constructs, as well as integrative and non-integrative systems approaches, the latter of which have presented major problems for iPSCs generation. Four main groups of different non-integrative approaches are available: integration-defective viral delivery, episomal delivery, RNA delivery and protein delivery (González et al., 2011). There is no best reprogramming strategy that can be used to fit all purposes. The choice of the strategy highly depends on the purpose of the research; whether it focuses on understanding the mechanisms of reprogramming or on generating clinically relevant iPSCs. Integrative methods with lentiviruses can 
be sufficient for the former use while non-integrative approaches should be used for the latter to limit genomic modifications.

Understanding and treating many diseases have been constrained by the absence of in vitro models, especially because culturing primary cells affected by the diseases is very challenging. Limitations primarily lie in the access to patient's tissues as the priority goes for diagnosis, in addition to the complications in obtaining some cell types, such as neural or cardiac tissues, and to maintaining these cells in vitro. However, the development of stem cell studies and the novel discovery of iPSCs provided an important source of cells to conduct in vitro studies (Unternaehrer and Daley, 2011). Such establishment of human iPSCs (hiPSCs) has led to new clinical strategies for using them as universal sources in regeneration therapy of damaged organs and tissues (Pei et al., 2010). Moreover, iPSCs generated from a patient affected by a certain disease possibly reproduces the disease phenotype (Egashira et al., 2011). In view of this, different kinds of patient-specific iPSCs have been generated to model human neurodegenerative diseases, such as Parkinson's disease (PD) (Byers et al., 2012), Huntington's disease (HD) (Nekrasov et al., 2016), Amyotrophic lateral sclerosis (ALS) (Chestkov et al., 2014), and Alzheimer's disease (AD) (Mungenast et al., 2016).

\section{IPSCs AND ECTODERMAL DIFFERENTIATION}

The ectoderm is the first germ layer to emerge during gastrulation, which is initiated by the formation of the primitive streak within the epiblast. Cell lineages derived from the ectoderm differentiate to form mainly the epidermis (including skin, hair, nails, and sweat and sebaceous cutaneous glands) and the nervous system (central and peripheral). The development of the vertebrate nervous system is shown to be regulated temporally and spatially by gradients of signaling molecules that may have either inhibitory or activating roles. These molecules are important for neuronal migration (Khodosevich and Monyer, 2011), axonal guidance and outgrowth (Chilton, 2006), interneuronal synapses (Scheiffele, 2003) and neuron-glia interaction (Fields and Stevens-Graham, 2002). Subsequently, experiments have demonstrated that this process is under the control of a combination of smallmolecule endogenous inhibitors of bone morphogenic protein (BMP) and TGF $\beta /$ activin/nodal signaling (Morizane et al., 2011), which promote highly efficient neural induction from both human ESCs and iPSCs. Additionally, it was shown that DLK1 has a role in stimulating neurogenesis of human and mouse iPSC-derived neural progenitors via modulating Notch and BMP signaling (Surmacz et al., 2012). Using such small molecules to induce differentiation of iPSCs into a specified lineage shows a potent approach to generate specific cell types in order to better understand the biological function and disease processes, as well as to use these cells in drug screening and cell therapy.

\section{USE OF IPSCS TO MODEL NEURODEGENERATIVE DISEASES}

Recently, efforts have been dedicated to generate defined lineages of neural cells from ESCs and iPSCs. These cells serve to better understand the molecular mechanisms underlying the pathophysiology of many intractable neurodegenerative diseases such as PD, HD, ALS, and AD aiming for the development of effective therapies. The present lack of precise models of these diseases conveys the significant discrepancies in understanding the mechanisms underlying their pathophysiology. In the last decade, the ability to reprogram somatic cells into iPSCs have enhanced the effectiveness of human in vitro models of neurological diseases (Mungenast et al., 2016). Moreover, the differentiation of these iPSCs into diseaserelevant cell types have allowed comprehensive molecular analyses of multiple disease states. Indeed, neurons differentiated from patient-specific iPSCs provide a valuable tool to model specific molecular phenotypes of neurodegenerative diseases in vitro (Heman-Ackah et al., 2016). In this aspect, the introduction of human iPSCs with disease-specific genetic backgrounds requires precise and flexible genome engineering tools.

Among different groundbreaking experiments, the Clustered Regularly Interspaced Short Palindromic Repeats (CRISPR) endonuclease is considered the less cumbersome and the most flexible system to execute precise genome editing in human pluripotent stem cells (Kime et al., 2016). The genomic revolution made by this system and others, including the Zinc Finger Nucleases (ZFN) and Site specific nucleases (SPN), offered the simplest and most powerful approach toward manipulating the produced iPSCs for mimicking any disease and adding more advancement and efficiency to the resulting cells (Mandegar et al., 2016). Recently, Rubio et al. described a new platform where neurons can be generated in vitro and manipulated using CRISPR/Cas9 to inactivate specific genes associated with different neuropathologies in humans (Rubio et al., 2016). Moreover, in a recent study, it was shown that CRISPR can be used to exert precise alterations in the expression of the critical PD-related gene, SNCA, in human iPSC-derived neurons (Heman-Ackah et al., 2016). Remarkably, Paquet et al. (2016) established a procedure that allows the introduction of specific point mutations into iPSCs using CRISPR, thus generating human iPSCs with specific combinations of homozygous and heterozygous early-onset Alzheimer's-associated mutations. Certainly, the rapid development of iPSCs and genome-editing technologies are important tools for disease modeling that hold promise for applications in gene therapy.

In this review we will focus on the reprogramming of somatic cells into patient-specific hiPSCs to model four neurodegenerative diseases, namely Parkinson's disease (PD), Huntington's disease (HD), Amyotrophic lateral sclerosis (ALS) and Alzheimer's disease (AD), and other applications in neurotrauma, through summarizing the different protocols that are used in each for the reprogramming and differentiation processes (Figure 1). 


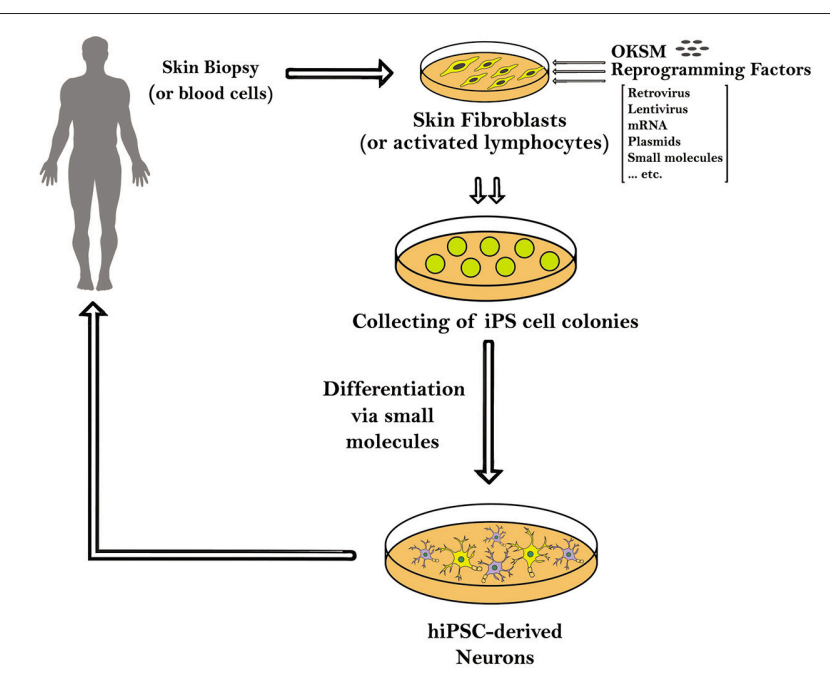

hiPSCs: human induced pluripotent stem cells OKSM: Oct4 ,Klf4, Sox2, c-Myc

FIGURE 1 | Schematic diagram showing the methods used to generate induced pluripotent stem cells (iPSCs) from human somatic cells as skin fibroblasts or blood cells. The hiPSCs derived from a patient carrying a certain genetic mutation in a neurodegenerative disease have the capacity to differentiate into different neurons. Those patient-specific hiPSCs and

hiPS-derived neurons can be expanded and further differentiated into mature neural subtypes specific to certain neurodegenerative diseases.

\section{iPSCs and Parkinson's Disease}

The study of Parkinson's disease (PD) is challenging due to the inaccessibility of affected human midbrain dopaminergic (mDA) neurons on which to base experimental research, and the rarity of animal models that follow the major disease characteristics. Despite this, it has been uncertain whether the involved mechanisms would also occur in human neurons affected by the disease. Consequently, molecular pathways underlying this pathology are still not well-defined. Although the majority of PD cases are sporadic, some rare familial forms of this disease have led to the discovery of PD-linked genes. This discovery was imperative for deciphering the cellular and molecular mechanisms of PD (Gasser, 2007; Schulz, 2008) and for creating transgenic animal and cellular models expressing these PDassociated genes. Recent development in PD research generated different neuronal cell types, which were previously inaccessible, by deriving PD-linked iPS cell lines that could be used for autologous transplantation (Park et al., 2008a; Soldner et al., 2009). Such approaches present exciting promises to elucidate the etiology of PD and develop novel potential therapeutics (Byers et al., 2012; Table 1).

DA neurons that were first generated from mouse iPSCs in 2008 and transplanted into the striatum of a rat PD model, have shown to ameliorate functional deficits (Wernig et al., 2008). Recently, human fibroblasts have also been used to produce PD patient iPS-cell derived DA neurons. Soldner et al. (2009) was the first to report efficient reprogramming of human skin fibroblasts from 5 patients with sporadic PD into
hiPSCs, and subsequent differentiation of these cells into DA neurons. Neural differentiation was first induced by embryoid body (EB) formation method in EB medium on non-adherent culture plates for 8 days, and then neural precursor cells were selected and cultured in ITS medium containing fibronectin, growth factors FGF2, FGF8, and sonic hedgehog (SHH). This was followed by withdrawal of growth factors for 8 days to attain terminal differentiation. Cells produced stained positive for tyrosine hydroxylase (TH) and neuron-specific class III- $\beta$ tubulin (TUJ1) confirming their DA neural nature (Soldner et al., 2009). Besides, the obtained hiPSCs, using the Cre-Recombinase excisable viruses, uniformly expressed the pluripotency markers Tra-1-60, SSEA4, OCT4, SOX2, and NANOG, in addition to possessing similar morphology to the human ESCs. Interestingly, the OCT4 promoter region of the obtained hiPSCs was in a hypomethylated state in contrast to the hypermethylated state which is found in the parental fibroblasts cells. There were also no differences in the ability or efficiency to differentiate dopaminergic cells from PD and non-PD patients (Soldner et al., 2009).

While sporadic PD cases are the most prevalent, and lack specific causative genes and a definite genetic basis, there still exists a barrier toward making any genotypic verification from the obtained differentiated cells (Park et al., 2008a). Previously, studies on PD animal models and ESC-derived dopaminergic transplantation has shown to be successful (Ganat et al., 2012; Grealish et al., 2014; Kang et al., 2014). Neuroprogenitor cells (NPCs) differentiated from iPSCs were transplanted in mouse fetal brain and were able to migrate into various regions of the brain, differentiate into both glia and neurons, and integrate into pre-existing brain network (Wernig et al., 2008). When neurons were transplanted, they exhibited a normal behavior and started branching and forming synapses. Eventually, they matured releasing dopamine and thus reducing the motor manifestations of PD in PD rat and monkey models (Wernig et al., 2008; Hallett et al., 2015; Han et al., 2015). Applying such cell therapy for PD in particular is very promising and is under a lot of extensive research for better optimization before reaching human clinical trials.

Although, the co-expression of TH and TUJ1 defines the stable phenotype of the produced DA neurons, studies have proven an additional role of the forkhead transcription factor, FoxA2 in maintaining this stability (Ferri et al., 2007; Kittappa et al., 2007). Further modifications were implemented using new phenotypic markers to show that ventral midbrain DA neurons were not previously obtained, and thereby three modifications were added to the previously established differentiation protocol (Sonntag et al., 2007) in order to generate DA neurons with maintained stable phenotype (Cooper et al., 2010). First, retinoic acid (RA) was added at an early phase and at low dose to improve the regional identity of neural progenitor cells. Second, a high activity form of human SHH was used to permit production of a large population of FOXA2+ neural progenitor cells in vitro. Finally, FGF8b was replaced by FGF8a, and WNT1 was added for robust generation of FOXA2+ DA neurons (Cooper et al., 2010).

In another study, iPSCs derived from skin biopsies of patients using either three (OSK) or four (OKSM) lentiviral factors 
TABLE 1 | Parkinson's disease modeled with patient-specific hiPSCs.

\begin{tabular}{|c|c|c|c|}
\hline Authors & Donor somatic cell used & Generated iPSCs used & Neuronal differentiation method and results \\
\hline Soldner et al., 2009 & Human skin fibroblasts & PD Patient-Derived hiPSCs & $\begin{array}{l}\text { EB formation method in EB medium on non-adherent culture } \\
\text { plates for } 8 \text { days, then selecting neural precursor cells and } \\
\text { culturing them in ITS medium containing fibronectin, growth } \\
\text { factors FGF2, FGF8, and SHH, followed by withdrawal of growth } \\
\text { factors for } 8 \text { days to attain terminal differentiation }\end{array}$ \\
\hline
\end{tabular}

Cooper et al., $2010 \quad$ Human skin fibroblasts PD Patient-Derived hiPSC lines

Using a high activity form of SHH and FGF8a, rather than FGF8b, and specific regionalization by RA, directly from EB stage, to produce DA neurons with maintained stability defined by an expression marker code of FOXA2/TH/ $\beta$-tubulin

\begin{tabular}{ll}
\hline Devine et al., $2011 \quad$ Human skin fibroblasts & $\begin{array}{l}\text { PD Patient-Derived hiPSC lines } \\
\text { with triplication ofSNCA }\end{array}$
\end{tabular}

Feeder-free floor plate induction, and dual SMAD inhibition for 1 day by Noggin, SB431542 and dorsomorphin, followed by $\mathrm{SHH}$, WNT1 and DKK1 blocking antibody treatment for 8 days, then switching culture conditions to promote maturation of DA neurons

Sánchez-Danés et al., 2012 Epidermal keratinocytes and PD Patient-Derived hiPSC lines dermal fibroblasts

Lentiviral vector-mediated engineering of hiPSCs to overexpress $\mathrm{Lmx1a}$ in neural progenitors in order to generate enriched populations of neurons with the characteristics of A9 ventral midbrain DA neurons

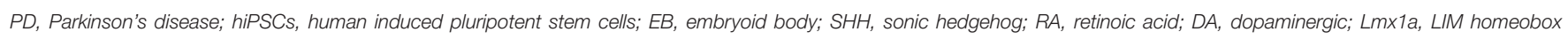
transcription factor 1a; DKK1, Dickkopf WNT signaling pathway inhibitor 1; SNCA, $\alpha$-synuclein gene.

were allowed to commence differentiation into DA neurons via dual SMAD inhibition for 1 day and feeder-free floor plate induction (Devine et al., 2011). Noggin (an inhibitor of BMP4) and SB431542 (an inhibitor of Lefty/Activin/TGF $\beta$ pathways) were used for this purpose, in addition to Dorsomorphin (a chemical BMP inhibitor) which acts as a partial substitute for Noggin. This was followed by SHH, WNT1, and Dickkopf WNT signaling pathway inhibitor 1 (Dkk1) blocking antibody treatment for 8 days, then switching the culture conditions to promote maturation of $\mathrm{mDA}$ neurons from neural progenitors (Devine et al., 2011).

Earlier in 2009, Cai et al. studied the role of LIM homeobox transcription factor 1a (Lmxla) in the differentiation of human ESCs into mDA precursor cells in vitro and after transplantation into a PD model (Cai et al., 2009). Lmxla is known to autoregulate and control $\mathrm{mDA}$ neurons synergistically with the SHH-FoxA2 pathway (Chung et al., 2009). Results have shown that only Lmxla-expressing human neuronal progenitor cells have the potential to differentiate into $\mathrm{mDA}$ neurons after transplantation into the 6-OHDA rat striatum (Cai et al., 2009). This is of great importance for the development of suitable re-placement tissue for the functional recovery from PD (Cai et al., 2009). Consequently, a complete potential of iPSCs to differentiate into DA neurons is revealed once EB cells, derived from iPSCs transfected by a lentivirus, were forced to express the ventral midbrain determinant Lmxla, together with DA neuron patterning factor. This resulted in the differentiation of EBs into functional mDA, the cell type mostly affected in PD (SánchezDanés et al., 2012).

Human iPSC-derived PD-cell models were later used to have a mechanistic insight into the gene-environmental interaction involved in the pathogenesis of $\mathrm{PD}$, such as the use of small-molecule high-throughput screening to identify new pathways (like MEF2C-PGC1 $\alpha$ pathway) as therapeutic targets to combat PD (Ryan et al., 2013). All in all, the main aim behind the use of iPSCs technology in this context remains to be able to convert this new knowledge of PD into effective therapeutic discoveries.

\section{iPSCs and Huntington's Disease}

Huntington's disease (HD) is an autosomal dominant neurodegenerative disorder caused by a CAG trinucleotide repeat expansion in the huntingtin gene that generates long polyglutamine stretches in the encoded huntingtin protein (HTT). This leads to a massive loss of medium spiny neurons in the striatum and loss of neurons in the cortex as the disease progresses. Personality changes, weight loss, involuntary movements and dementia are the principal changes mostly developed among the people carrying the huntingtin gene mutation.

Transgenic mouse models of HD expressing exon 1 of the human HD gene were developed to mimic the features of the human HD. The R6/2 mouse model has represented the most rapid symptoms with widespread huntingtin inclusions in the brain (Mangiarini et al., 1996; Li et al., 2005; Gil and Rego, 2009). Some therapeutic approaches of neuronal transplantation were analyzed in R6/2 mice aiming to restore dysfunctional neurons. Transplantation of striatal tissue from wild type mice embryos in R6/2 transgenic mice presented a good survival and a well-integrated results within the host brain. However, it was associated with minimal behavioral improvements and no effect on weight loss, which might be due to late transplantation intervention (Dunnett et al., 1998; Gil and Rego, 2009). A more recent protocol combined neural stem cells (NSCs) transplantation with a trehalose enriched diet in R6/2 mice and resulted in more improved motor functions, less aggregations in 
TABLE 2 | Huntington's disease modeled with patient-specific hiPSCs.

\begin{tabular}{|c|c|c|c|}
\hline Authors & Donor somatic cell used & Generated iPSCs used & Neuronal differentiation method and results \\
\hline Park et al., 2008a & Human dermal fibroblasts & $\begin{array}{l}\text { Patient specific HD-iPSCs } \\
\text { with } 72 \text { CAG repeats in } \\
\text { huntingtin gene }\end{array}$ & $\begin{array}{l}\text { Resuspending HD-iPSC colonies in EB differentiation medium in the } \\
\text { absence of doxycycline }\end{array}$ \\
\hline Zhang et al., 2010 & Human dermal fibroblasts & Patient specific HD-iPSCs & $\begin{array}{l}\text { Treating HD-NSCs with SHH, DKK1, BDNF and ROCK inhibitor Y27632 for } \\
\text { 8-10 days (stage 1), then with BDNF, CAMP, VPA, and Y27632 for an } \\
\text { additional } 1-3 \text { days (stage 2) }\end{array}$ \\
\hline Camnasio et al., 2012 & Human skin fibroblasts & Patient specific HD-iPSCs & $\begin{array}{l}\text { (Chambers et al., 2009) neural differentiation protocol used revealing that } \\
\text { the lengths of CAG trinucleotide repeats in the generated neurons is not } \\
\text { affected by the differentiation process }\end{array}$ \\
\hline
\end{tabular}

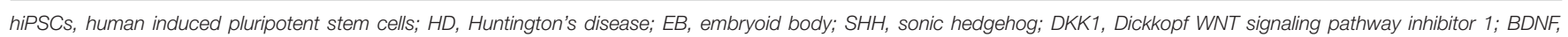
brain-derived neurotrophic factor; VPA, valproic acid; HD-NSCs: HD, specific neural stem cells.

striatum and extended the lifespan of the animals (Yang and $\mathrm{Yu}$, 2009). This further supports the importance of generating human and patient specific HD-iPS neuron cell models with endogenous CAG expansion to be used for cell replacement therapies as well as for drug screening and to enrich our knowledge in understanding mechanisms of HD (Table 2). The generation of efficient protocols for the differentiation of iPSCs into enriched populations of GABA MS-like neurons (GMSLNs) is indeed needed to provide a good model to investigate the disease manifestation and drug development (Nekrasov et al., 2016). HD-specific iPSCs were first generated in 2008 by Park et al. and they expressed an expanded CAG repeat sequences (72 repeats). The iPSCs were then differentiated into neural precursors by resuspending colonies in EB differentiation medium in the absence of doxycycline with low-speed shaking (Park et al., 2008a).

Later in 2010, Zhang et al. piloted a study to differentiate and characterize human HD cell model from iPSCs (Zhang et al., 2010). Their iPSC cell model had CAG repeats of the same length as the parental fibroblast cells (72 repeats). Neural induction of these HD-iPSCs was achieved using the previously established EB differentiation method (Park et al., 2008a). Thereafter, further differentiation of the HD-specific NSCs (HD-NSCs) into striatal neurons was carried out by treating them directly with $\mathrm{SHH}$, DKK1, brain-derived neurotrophic factor (BDNF) and ROCK inhibitor Y27632 for 8-10 days as an initial step (stage 1), then with BDNF, cAMP, VPA and Y27632 for an additional 1-3 days (stage 2). At stage 1, cells stained positive for the neuronal markers TUJ1 and GABA, as well as calbindin. Mature striatal neurons at stage 2 expressed, in addition to the aforementioned three markers, an additional medium spiny neuron marker DARPP-32, thus confirming their striatal nature (Zhang et al., 2010).

To assess whether the length of the pathological CAG repeat in GABAergic neurons derived from HD-iPSCs is affected during lentiviral reprogramming, a study was conducted showing that neither the long-term growth of reprogrammed HD-iPSCs in vitro nor the differentiation process affects the lengths of CAG trinucleotide repeats in these neurons (Camnasio et al., 2012). In this study, the neural differentiation protocol described by Chambers et al. was used (Chambers et al., 2009), where it is shown that the synergistic action of two SMAD signaling pathway inhibitors, Noggin and SB431542, is sufficient to induce rapid and complete neural differentiation. These advances in the use of HDspecific iPSCs and neurons differentiated from them may provide a powerful platform for target identification and drug screening in HD.

\section{iPSCs and Amyotrophic Lateral Sclerosis}

Amyotrophic lateral sclerosis (ALS) is an incurable neurodegenerative disorder that leads to the loss of upper and lower motor neurons. It has a genetic background in which $10 \%$ of the cases have a positive family history of mutations in the superoxide dismutase 1 (SOD1) gene which is associated with the most common familial form of ALS. In addition, there is an estimate of 30 genes directly linked to the pathophysiology of the disease, including TARDBP, FUS, OPTN, VCP, UBQLN2, C9ORF72, PFN1... etc., and over 120 other genes indirectly associated with ALS (Abel et al., 2012). Generation of iPSCs from patients with ALS and their differentiation into motor neurons was first reported in 2008 (Dimos et al., 2008; Table 3). In his study, Dimos et al. (2008) used skin fibroblasts collected from an 82-year-old patient diagnosed with familial ALS to produce patient-specific iPSCs. These cells were subsequently plated in suspension culture to form EBs, then treated with $\mathrm{RA}$ and recombinant $\mathrm{SHH}$ to persuade neural differentiation. When these differentiated EBs were plated on a laminin-coated surface and allowed to mature for 7-15 days, they started forming neuron-like outgrowths that stained positive for TUJ1, confirming their neuronal nature.

Recently in 2014, researchers were able to obtain iPSCs from patients with familial forms of SOD1-mediated ALS by using lentiviral reprogramming system (Chestkov et al., 2014). Using a similar method to Dimos et al. (2008) and Chestkov et al. (2014) generated patient specific iPSC cells carrying the SOD1 mutation from primary skin fibroblasts. The resulting iPSCs expressed the same SOD1 gene mutations as the respective patients and no differences were detected among the iPSCs of the different patients with different genotypes. After 12 days, these cells were directly differentiated into motor neurons by adding $\mathrm{RA}$ and $\mathrm{SHH}$ to the culture medium. Additionally, BDNF and glial cell line-derived neurotrophic factor (GDNF) were used for the maturation of the motor neurons. These cells also expressed TUJ1 neuronal marker (Chestkov et al., 2014) but their advantage over the model of Dimos et al. (2008) was mainly due to the 
TABLE 3 | Amyotrophic lateral sclerosis modeled with patient-specific hiPSCs.

\begin{tabular}{|c|c|c|c|}
\hline Authors & Donor somatic cell used & Generated iPSCs used & Neuronal differentiation method and results \\
\hline Dimos et al., 2008 & Human skin fibroblasts & $\begin{array}{l}\text { Patient-specific iPSCs carrying SOD1 } \\
\text { gene mutation (with L144F dominant allele) }\end{array}$ & $\begin{array}{l}\text { Allowing iPSCs to form EBs in suspension culture, then treating } \\
\text { them with RA and recombinant } \mathrm{SHH} \text { to induce neural } \\
\text { differentiation, and finally plating them on a laminin-coated surface } \\
\text { and culturing for } 7-15 \text { days }\end{array}$ \\
\hline Chestkov et al., 2014 & Human skin fibroblasts & $\begin{array}{l}\text { iPS cell lines from patients with SOD1- } \\
\text { associated ALS }\end{array}$ & $\begin{array}{l}\text { Adding RA and SHH to mTeSR1 culture medium } 12 \text { days after } \\
\text { iPSCs generation, then maturation of the produced motor neurons } \\
\text { using BDNF and GDNF }\end{array}$ \\
\hline Li et al., 2015 & Human skin fibroblasts & $\begin{array}{l}\text { Familial ALS patient-specific iPSCs, } \\
\text { carrying different ALS mutations, including } \\
\text { SOD1 and FUS }\end{array}$ & $\begin{array}{l}\text { Differentiation to NPCs by inhibition of SMAD pathway via EB } \\
\text { formation assay }\end{array}$ \\
\hline
\end{tabular}

iPSCs, induced pluripotent stem cells; SOD1, superoxide dismutase 1; ALS, Amyotrophic lateral sclerosis; FUS, fused in sarcoma gene; EB, embryoid body; RA, retinoic acid; SHH, sonic hedgehog; BDNF, brain-derived neurotrophic factor; GDNF, glial cell line-derived neurotrophic factor; NPCs, neuroprogenitor cells.

presence of the mTeSR1 in medium that helped in maintaining the pluripotent state needed for the unlimited production of motor neurons (Chestkov et al., 2014). That being said, it had been shown that mTeSR1 medium supports stem cell growth by containing agonists of signaling systems, such as GABA receptors and ErbB2, which while less characterized, are thought to play a role in human ESCs maintenance (The International Stem Cell Consortium Initiative Consortium et al., 2010). Nevertheless, many other media, like DMEM/F12 medium with $20 \mathrm{ng} / \mathrm{mL} \beta$ FGF (Cai et al., 2009), that has been used for maintaining iPSCs, are also capable of avoiding uncontrolled differentiation of those iPSCs.

Moreover, astroglia were derived from iPSCs obtained from an ALS patient carrying the TARDBP mutation in order to investigate the suspected role of glial cell activation in ALS pathogenesis. These derived astroglia showed TDP-43 (the protein product) proteinopathy, such as mislocalization of TDP43 , increased total cellular levels of TDP-43, and decreased cell survival. However, upon co-culture of the derived astroglia with derived motor neurons from the same iPSCs of the ALS patient or from control normal patients, there were no effects of any kind on the neurons in culture suggesting other involved mechanisms as previously described for SOD1 ALS (Serio et al., 2013). In this context, motor neurons were successfully differentiated from iPSCs of an 82 year old patient with familial ALS of this same TDP-43 mutation (Dimos et al., 2008). Besides, iPSCs have been derived from ALS patients carrying the C9ORF72 mutation which is also involved in frontotemporal dementia and these have also uncovered some characteristic phenotypes in ALS (Donnelly et al., 2013; Sareen et al., 2013; Hedges et al., 2016). All this further supports the notion of iPSCs' culture studies as models unraveling a lot that needs to be known about neurodegenerative disease such as ALS that we know about the very little.

Although motor neurons have been successfully produced via differentiation of ALS-iPSCs, no reports indicated whether SOD1 mutation interferes with this differentiation. Therefore, Li et al. tackled this issue in 2015 (Li et al., 2015) whereby ALS-iPSCs were derived from fibroblasts using retroviruses. This was followed by differentiation into NPCs via EB formation assay by inhibiting the SMAD pathway. Interestingly, no significant differentiation differences were seen between control and SOD1-iPSCs, suggesting that SOD1 mutation has no obvious effects on neural induction. Moreover, NPCs were treated with fetal bovine serum (FBS) to induce astroglia formation, which successfully expressed the astroglia progenitor marker CD44. It is noteworthy mentioning that generation and maturation of iPS derived-astroglia takes a long time in vitro, providing a platform to screen drugs that may be used to enhance astroglia development and maturation (Li et al., 2015). Some late studies have also suggested a role for astrocyte pathogenesis in ALS that also express the mutant SOD1 gene contributing to the death of motor neurons (Di Giorgio et al., 2007; Nagai et al., 2007). This authenticates the importance of iPSCs technology in studying both neuronal and astrocytic cell lineages to uncover the mechanism of action of riluzole and to discover new drugs that might provide a ray of hope for ALS patients.

Up till now, FDA has only approved one drug, riluzole, for ALS which acts by delaying progression of the disease but has no assertive efficacy in increasing survival (Cheah et al., 2010). This authenticates the importance of iPS cell technology in providing a ray of hope for those patients who continue to suffer the lack of an effective remedy for their condition.

\section{iPSCs and Alzheimer's Disease}

Alzheimer's disease (AD) is the most common form of agerelated dementia (Alzheimer's Association, 2010), characterized by progressive cognitive disturbance and loss of memory. It is famously distinguished by the presence of two major hallmarks: extracellular accumulation of amyloid beta $(A \beta)$ plaques and intracellular aggregation of the microtubule associated protein, tau. AD exists in as little as $1-5 \%$ in its familial form, characterized by autosomal dominant inheritance of Presenilin1 or -2 or/and Amyloid Precursor Protein (APP), while the majority of $\mathrm{AD}$ cases to date are sporadic and multifactorial with suspected role of epigenetics involved in the course of progression. List of suspected genes include $M A P T, B A C E 1$, $B A C E 2, A D A M 10, A D A M 17$, and others (Karch and Goate, 2015).

This neurodegenerative disease is under extensive study for therapeutic options including cell-replacement based therapy. The need for urgent therapy stems from the fact that a small percentage of all $\mathrm{AD}$ patients get moderate improvement from 
TABLE 4 | Alzheimer's disease modeled with patient-specific hiPSCs.

\begin{tabular}{|c|c|c|c|}
\hline Authors & Donor somatic cell used & Generated iPSCs used & Neuronal differentiation method and results \\
\hline Yagi et al., 2011 & Human skin fibroblasts & $\begin{array}{l}\text { AD-derived iPS cell lines with PS } \\
\text { mutations (PS1 and PS2 iPSCs) }\end{array}$ & $\begin{array}{l}\text { PS mutations in familial AD shown not to affect neuronal } \\
\text { differentiation }\end{array}$ \\
\hline Yahata et al., 2011 & Human dermal fibroblasts & AD-derived iPSCs & $\begin{array}{l}\text { Differentiation of hiPSCs into forebrain neurons achieved using } \\
\text { protocol described by Chambers et al. (2009; Using two SMAD } \\
\text { signaling pathway inhibitors, Noggin and SB431542, for rapid and } \\
\text { complete neural differentiation), and additionally induced with } \\
\text { Noggin and SB431542 for } 17 \text { days }\end{array}$ \\
\hline Nieweg et al., 2015 & $\begin{array}{l}\text { Human cord blood-derived } \\
\text { unrestricted somatic stem cells } \\
\text { (Zaehres et al., 2010) }\end{array}$ & $\begin{array}{l}\text { hiPSC line 8/25 derived from human } \\
\text { cord blood-derived unrestricted somatic } \\
\text { stem cells (Zaehres et al., 2010) }\end{array}$ & $\begin{array}{l}\text { hiPSC line } 8 / 25 \text { cultured in mTeSr medium and differentiated into } \\
\text { neural cells according to a modified protocol by Li et al. (2009), } \\
\text { where a neural medium was used that comprises of N2B27 } \\
\text { medium ( } 50 \% \text { DMEM/F12, 50\% Neurobasal), Glutamax, penicillin, } \\
\text { streptomycin, modified N2 supplement, } \beta \text {-mercaptoethanol, B27 } \\
\text { without vitamin A and heparin }\end{array}$ \\
\hline
\end{tabular}

hiPSCs, human induced pluripotent stem cells; PS, Presenilin; AD, Alzheimer's disease.

all available $\mathrm{AD}$ drugs and a significant number of those patients suffer major side effects (Serretti et al., 2007). It is consistent that in $\mathrm{AD}$ animal models, there is decrease in neurogenesis in the subventricular and subgranular zones that get initiated early before $A \beta$ plaque formation suggesting decreased neurogenesis and progressive neuronal loss as pathologies of $\mathrm{AD}$ (Yang et al., 2016).

Transplantation of cholinergic precursors differentiated from iPSCs into $\mathrm{AD}$ transgenic mice proved to restore spatial memory impairment and survival of the cells transplanted (Fujiwara et al., 2013). A particular study reported that medial ganglionic eminence-like progenitors obtained from iPSCs differentiation, completed their maturation into the forebrain as GABAergic interneuron subtypes with mature physiological properties within a prolonged period of time that extended until 7 months, thus mimicking endogenous human neural development (Nicholas et al., 2013).

Yet, the difficulty of obtaining live neurons from patients, and the incapacity to pattern the sporadic form of the disease, still represents a limitation in the understanding of AD. Nevertheless, it is now possible to surmount this problem by simply obtaining fibroblast from skin biopsy of these patients and then generating disease specific iPSCs, which would serve as a model to enrich our knowledge in this disease (Table 4).

Yagi et al. (2011) and Yahata et al. (2011), were the first to generate hiPSCs from human fibroblasts in 2011. Differentiation of hiPSCs into forebrain neurons was achieved as described previously by Chambers et al. (2009). In addition, NSCs were induced with Noggin and SB431542 for 17 days to obtain cells that stained positive for the neuroectodermal marker, Nestin (Yahata et al., 2011). The presenilin (PS) mutations in familial $\mathrm{AD}$ were proved not to affect neuronal differentiation, where the ability to generate neurons $(\sim 80 \%$ TUJ1-positive cells) was comparable between PS-iPSCs and control iPSCs (Yagi et al., 2011). Noteworthy, the differentiated cells expressed APP, $\beta$-secretase, and $\gamma$-secretase components, and were found to secrete $A \beta$ into the conditioned media in addition to expressing a glutamatergic phenotype. Another important finding was that neurons differentiated from iPSCs of familial AD patients with PS1 and PS2 mutations exhibited increased production of $A \beta-42$, and tau protein was found hyperphosphorylated thus further showing that the differentiated iPSCs truly recapitulate the pathogenesis of $\mathrm{AD}$ (Yagi et al., 2011).

In a recent work published in 2015, Nieweg et al. used human iPSC-derived cortical neurons, differentiated using an EB system similar to that applied by Li et al. (2015), to produce a highly reproducible cellular $\mathrm{AD}$ model that facilitates the mechanistic analysis of $\mathrm{A} \beta$-induced synaptic pathomechanisms and the development of new therapeutic approaches (Nieweg et al., 2015). The differentiation protocol described by Li et al. states culturing iPSCs in a neural medium comprising Dulbecco's Modified Eagle Medium (DMEM)/F12, N2 supplement and heparin without growth factors (Li et al., 2009). Nieweg et al. (2015) used a modified medium that comprises of N2B27 medium (50\% DMEM/F12, 50\% Neurobasal), Glutamax, penicillin, streptomycin, modified N2 supplement, $\beta$-mercaptoethanol, $1 \%$ B27 without vitamin $\mathrm{A}$ and heparin. In the same paper, an attempt was made to recapitulate the synaptotoxicity of $A \beta$ which is crucial for understanding the cascade of events leading to cell death and continuous brain degeneration. The cells were differentiated into deep layer cortical pyramidal neurons and GABAergic interneurons; and upon longer cultivation, these cells exhibited action potential generation and excitatory and inhibitory synapses. Yet, most interesting was that these ADderived neurons were very susceptible to $A \beta$ synaptotoxicity (Nieweg et al., 2015). In a study on epigenetic characterization of iPSCs DA differentiated neurons, there was significant difference in global gene expression and DNA methylation as compared to the in vivo DA cells (Roessler et al., 2014). Therefore, epigenetic changes seem to leave their mark on the genome even beyond de-differentiation and this is mainly considered a limitation for applying iPSCs in human therapies. Since the cells in these experiments were needed to be passaged and tested at several time points, trans-differentiation does not seem to be the proper method for such application. Yet, all these models offer valuable 
insight about $\mathrm{AD}$ and understanding its progression and further designing therapeutics.

\section{IPSCs AND SPINAL CORD INJURIES}

In case of injury, the spinal cord does not spontaneously regenerate itself and till now there is not one available treatment that can provide the least functional recovery from SCI. The level at which the injury is present determines the symptoms and consequent motor manifestations. To date, cervical SCIs account for the majority of presented SCI cases (Doulames and Plant, 2016).

Many previous cell transplantation therapies have been approached such as peripheral nerve bridges, Schwann cells, olfactory glia, mesenchymal stem cells and NSCs (Plant et al., 2001; Barry and Murphy, 2004; Ramer et al., 2004; Cummings et al., 2005; Parr et al., 2008). Such therapies function to ameliorate the existing damage and prevent its further exacerbation by providing a scaffold to bridge the lesion, replace the host dead or lost neurons or glia, promote axonal regeneration and overcome glial scar formation (Bregman et al., 1997; Jones et al., 2001; Raisman, 2001; Ikegami et al., 2005; Donnelly and Popovich, 2008). In SCI, the main drawback to regeneration is the inability of the CNS neurons to regenerate axons that can cross through the inhibitory milieu of the glial scar and the injured lesion (Horner and Gage, 2000). Certain studies on rats showed promise that this can be overcome by using iPSCs as these reprogrammed iPSC neurons can extend many axons over very long distances and form synapses with host rat neurons (Parr et al., 2008; Romanyuk et al., 2015).

The implementation of iPSCs offers a great mean of cellbased therapy capable of bypassing the usual ethical dilemma associated with ESCs. The iPSCs have the ability to differentiate into tissue-specific neurons which leads to long-term restoration of the lesioned tissue (Romanyuk et al., 2015). Moreover, these cells can be obtained in a non-invasive patient-specific manner that makes iPSC an even more approachable attractive candidate for SCI therapy. This cell replacement therapeutic approach has opened a new era in the field of regenerative medicine.

Jin Young Hong and colleagues generated self-renewable induced NSCs from somatic fibroblasts and engrafted them in a rat model of SCI. The engrafted cells were able to restore axonal regeneration resulting in recovery of motor, sensory and autonomic functions (Hong et al., 2014). In another study, Pajer et al. performed avulsion of the lumbar 4 (L4) ventral root in rats, an injury that is known to induce the death of majority of affected motor neurons. Afterwards, they transplanted murine iPSCs into the injured spinal cord segment. Their observation included improved re-innervation by the host motor neurons as compared to controls with no iPSC transplantation procedure. It also seemed that the observed morphological re-innervation resulted in functional recovery as the grafted rats exhibited more motor movement units in their re-innervated limb than controls. This study also established that the grafting of iPSCs downregulated astroglial activation in the injured site and was able to conclude that the observed motor neuron survival and regeneration came as a result of neurotrophic and cytokine modulatory mechanisms (Pajer et al., 2015). Furthermore, a study performed on mice suggested that the neurons derived from the transplanted cells functioned as interneurons in the mouse spinal cord which in turn contributed to the reconstruction of neural circuits (Nakamura and Okano, 2013). Moreover, neural precursors derived from a clone of hiPSCs (IMR90) were used to treat a rat spinal cord lesion 1 week after induction. These hiPSC-neural precursors robustly survived in the lesion, migrated, and partially filled the lesion cavity during the entire period of observation. Transplanted animals displayed significant motor improvement already from the second week after the transplantation (Romanyuk et al., 2015).

The application of iPSCs seems so good so far and all these mentioned results raise great clinical expectations. However, it should be noted that safety-related concerns for such iPSCs cell therapy should be resolved prior to clinical application. A main concern after iPSC therapy is tumor formation as a result of residual or remaining undifferentiated iPSCs that were not successfully induced into differentiation. Moreover, there is the chance that the reprogramming was not necessarily complete (Nakamura and Okano, 2013; Kim et al., 2014). Long term safety issues also include deteriorated motor function accompanied by a tumor formation (Nori et al., 2015). However, Tsuji et al. used the neurospheres 3D culturing of iPSCs obtained from mice fibroblasts, and injected them into the injured spinal cord. Those neurospheres were able to differentiate into three neuronal lineages: astrocytes, oligodendrocytes, and neurons, promoting recovery and improving locomotor functional loss with no tumor formation for the observation period of more than 120 days (Tsuji et al., 2010). Besides, an in vivo study has shown that 3 rats have died out of 12 rats that received transplantation with DA neurons derived from protein based iPSCs (Rhee et al., 2011). The rats that died showed tumor formation after 8 weeks from grafting. Moreover, in a comparison between transplanted secondary neurospheres derived from iPSCs generated in 11 different ways and neurospheres from ESCs, the former showed a significant teratoma formation propensity most likely correlated with the persistence of undifferentiated cells (Miura et al., 2009). All this further halts the use of such a therapeutic tool in humans as much still needs to be optimized.

Researchers at the University of California, San Diego School of Medicine launched a 5-year clinical trial program starting 2014 in order to investigate the safety of NSCs transplantation in patients with chronic SCIs (University of California 2014). A recent clinical trial on humans, the SciStar study, has been using oligodendrocyte progenitors to treat people with recent SCIs. This study not only has proven to be effective so far but has lately passed major safety issues and therefore was approved to expand by increasing the number of both enrolled patients and the transplanted cells per patient (California Institute for Regenerative Medicine (CIRM) 2016). Although this study aims at evaluating the safety and effectiveness of AST-OPC1 agent, which consists of oligodendrocyte progenitor cells produced from human ESCs, in patients with recent SCI, results can be promising as regards potential use of iPSCs instead of human ESCs in this context. 


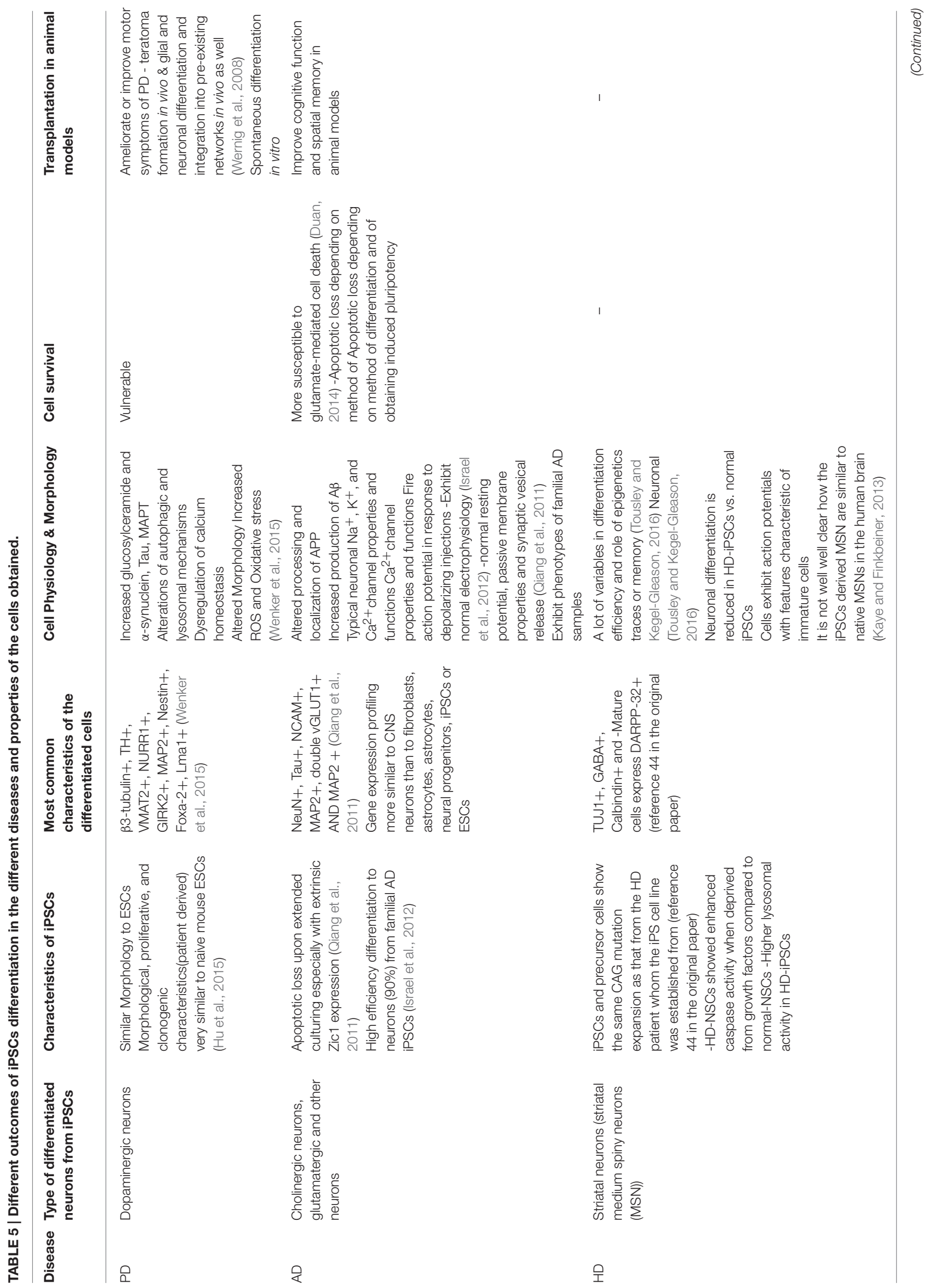




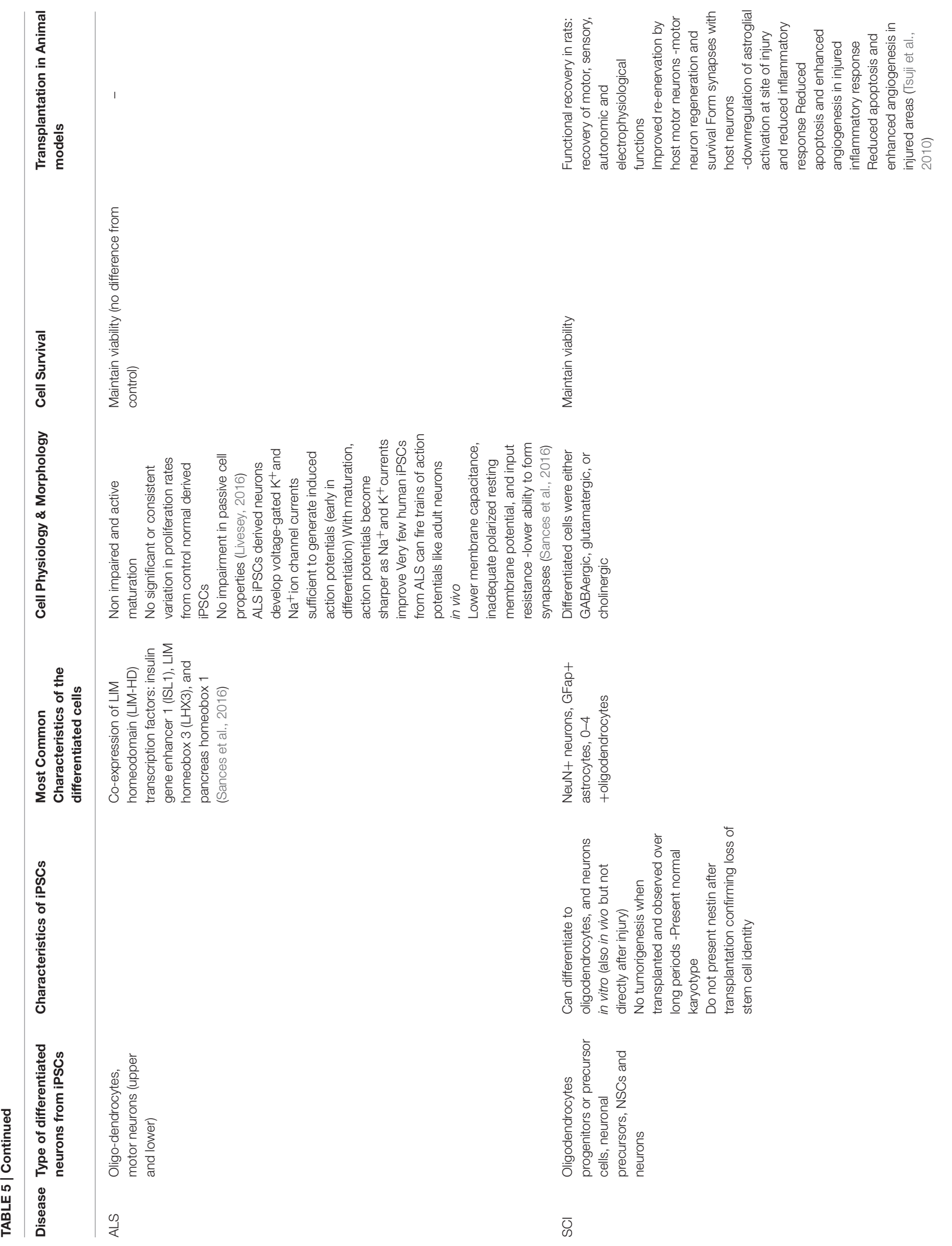




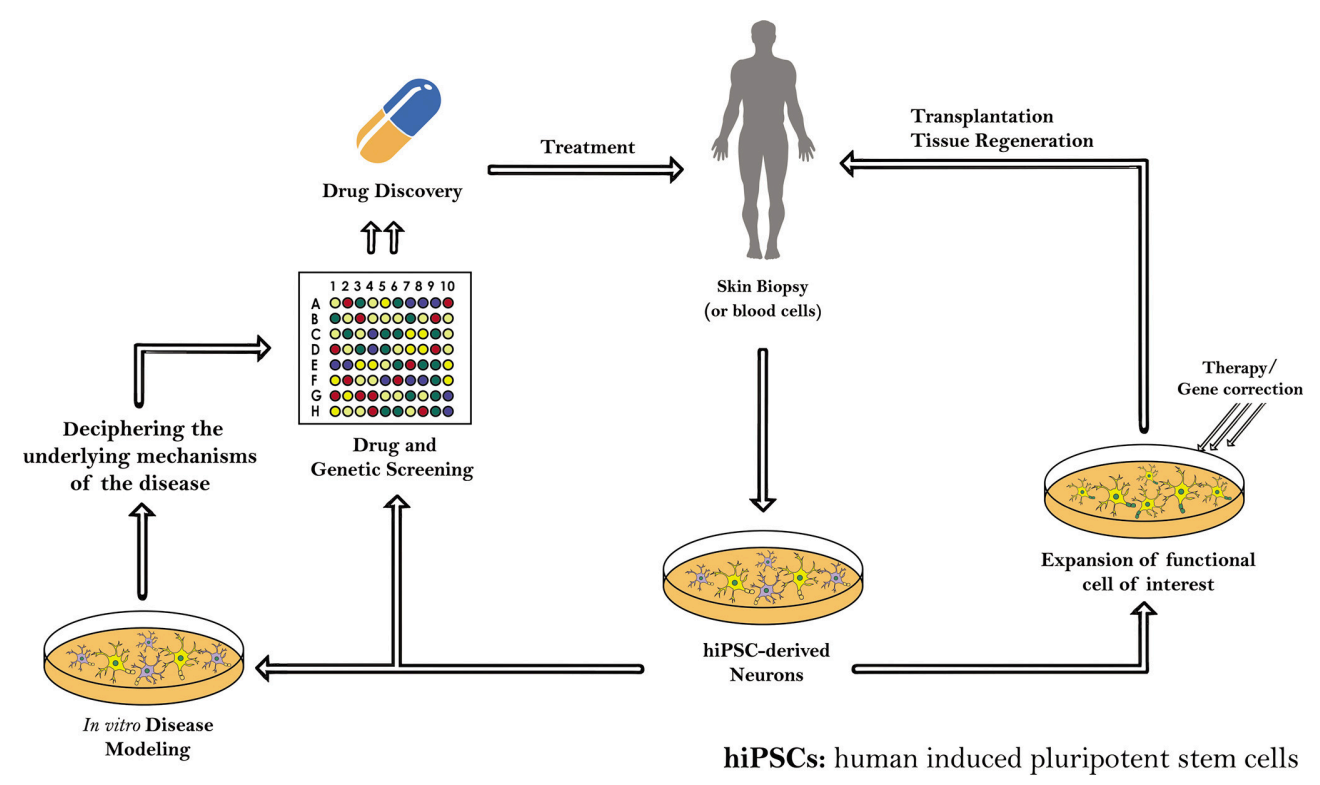

FIGURE 2 | Schematic diagram demonstrating the different applications of induced pluripotent stem cells (iPSCs) derived from human somatic cells. The patient-specific hiPSCs and hiPS-derived neurons can serve as precursors for transplantation and tissue regeneration therapy. hiPSCs generated are also a copious resource for in vitro and in vivo disease modeling, drug and genetic screening, and regenerative medicine.

\section{STROKE, BRAIN INJURY AND iPSCs}

Oki et al. (2012) provided the first evidence that transplantation of hiPSC-derived cells is a safe and efficient approach to promote recovery after stroke and can be used to supply the injured brain with new neurons for replacement. They transplanted neuroepithelial-like stem cells, generated from adult human fibroblast-derived iPSCs, into stroke-damaged mouse and rat striatum or cortex. The transplanted cells stopped proliferating after a while but have at least shown that they can survive without forming tumors for at least a period of 4 months. This 4-months observation period warrants lack of rejection of the transplanted cells and creates an optimal setting to evaluate tumorigenicity. The iPSCs successfully differentiated neurons in intrastriatal grafts sent axonal projections to the globus pallidus. Moreover, the grafted cells exhibited electrophysiological properties of mature neurons and most importantly received synaptic input from host neurons (Oki et al., 2012). There is not much data and research on the iPSCs regenerative ability in brain injury. Therefore, in order to establish its safety and effectiveness, much more studies and effort have to be done in that domain. After all, transforming such data to clinical trials in humans would be a great achievement toward finding a treatment and getting more insight on the brain circuitry itself.

\section{LIMITATIONS OF IPSCs USE IN NEURODEGENERATIVE DISEASES}

While the iPSCs technology holds the promise to becoming an efficient therapy for many neurodegenerative diseases that currently have no cure, there remains the risk of encountering multiple unanticipated outcomes when applying them on humans. The risks range from unwanted biological effects and immune response, toxicity, neoplasm formation, disease transmission, reactivation of latent viruses, to rejection of the cells by the body. It is difficult to determine and pinpoint the risks as they depend on several factors, including the cells that are used to achieve pluripotency, the status of the differentiated cells, their proliferation capacity, the technique of administration of the pluripotency genes, the level of manipulation, the growth factors used, the dilemma of retaining epigenetic memory, the intended site of injection, the reversibility or even irreversibility of the applied treatment, the susceptibility of the administered cells for disease, the incomplete suppression of the four transgenes after differentiation, the persistence of undifferentiated cells, and the survival of the transplanted cells in vivo (Okita et al., 2007). The known risks so far that were obtained mostly from animal models include tumor formation, unwanted immune responses and the transmission of certain adventitious agents (Herberts et al., 2011; Okano et al., 2013). Unfortunately, an estimated 20\% of mice that received iPSCs were found to develop tumors (Abdullah et al., 2012). Furthermore, it has been hypothesized that the sustained expression of the transgenes might have the ability to change the expression of certain oncogenes or tumor suppressor genes thus altering the tumorigenic potential of the cells. The c-Myc is a risk factor by itself as it is upregulated in naturally occurring tumors.

An important risk of iPSC therapy is associated with using lentiviruses or retroviruses. These viruses, although are genetically tailored to hold the genes required for an iPSC state transformation, will integrate into the host cell genome and consequently add multiple viral integration sites and be the cause 
for several safety issues (Howe et al., 2008). However, it should be noted that much control was gained over this process as the viral integration site can be determined in iPSCs using Cre-mediated strategies for instance or by using adenoviruses, plasmids, transposons, recombinant proteins, Sendai virus vectors and modified RNA (Herberts et al., 2011). It should be further noted that there has been worries of a state of dedifferentiation or dedifferentiation into an unwanted cell type once transplanted to humans, though this remains clinically unclear. Therefore, there has to be a thorough consideration of all the suspected risk factors before setting into iPSCs human clinical trials.

Trans-differentiated neurons offer a way to bypass the tumorigenicity risk associated with passing through a pluripotency state. This method allows lineage reprogramming as in directly converting a somatic cell type into another through transgenic expression of transcription factors or miRNAs. On the other hand, the procedure of re-differentiating iPSCs into specific cell types is considered lengthy, costly and arduous. In addition to that, having multiple stages before reaching the intended outcome may lower the efficiency of the generated cell type. So far, in this context, trans-differentiation seems to be also an interesting path in research that also offers the same concept of therapeutic approaches and disease modeling as iPSCs. Trans-differentiated cells show no tumorigenicity when transplanted in vivo, plus these cells show similar functionality to cells derived from iPSCs (Lopez-Leon et al., 2014; Hou and $\mathrm{Lu}, 2016)$. In the presence of an insult or a lesion, or even in $\mathrm{AD}$ animal models, glial cells can be successfully transformed to functional neurons by single transcription factor intervention (Guo et al., 2014). For example, in the presence of SOX2 in the injured adult spinal cord, astrocytes convert to double cortin (DCX) positive neuroblasts (Lau et al., 2014). However, the major limitation for trans-differentiation to be a therapeutic approach is that the obtained population of induced neurons has little to no proliferation rate, therefore directly restricting the efficiency and expansion of this technique (Hou and Lu, 2016). Hence, a better investment for a drug or therapeutic or modeling purposes would still be iPSCs, but this does not overthrow the importance of trans-differentiation. The research in this field is still young but so vivid and fertile that we can witness iPSCs applied in neurodegenerative diseases treatments in not the so far future. Yet, until this day, there is no recorded iPSCs treatment application on humans (Trounson and DeWitt, 2016).

\section{CONCLUSION AND PERSPECTIVES}

Although, iPSCs research has been a revolution in the scientific field as it provides new hope for the treatment of many diseases, protocols describing the differentiation of iPSCs into neural cells in neurodegenerative diseases and in the context of neurotrauma are still being modified and studied to assess the effect of this process on gene mutations in these cells and vice versa. Advances have been made recently to uncover the underlying molecular pathways of several neurodegenerative diseases, yet more work has to be done before one can say complete cure from such disorders is possible.

A recent approach of generating 3D brain tissues, namely "cerebral organoids", closely reproduces the endogenous developmental program. This approach can give rise to retinal identities, ventral telencephalon, developing cerebral cortex, and choroid plexus, within 1-2 months (Lancaster and Knoblich, 2014). Recent development of these 3D brain organoids derived from human iPSCs is a promising technology for understanding the development of in vitro disease models and investigating in particular the human polygenic disorders where animal models are not sufficient (Lindborg et al., 2016; Quadrato et al., 2016).

Yet, many hitches like mutations, incomplete epigenetic reprogramming and tumors formation, which accompany the use of iPSCs, should be solved as well. Therefore, further understanding of iPSCs, including a genome-wide epigenetic characterization of those cells and further studying of their genomic stability, is needed before beginning their clinical applications in the area of regenerative medicine for treating human diseases, mainly the intractable ones (Table 5). Indeed, these patient-specific hiPSCs will serve in the future as precursors for transplantation and tissue regeneration therapy, as well as a copious resource for in vitro and in vivo disease modeling and drug and genetic screening (Figure 2).

\section{AUTHOR CONTRIBUTIONS}

$\mathrm{HB}, \mathrm{OH}, \mathrm{FC}$, and WA worked on study conception and design. $\mathrm{HB}, \mathrm{OH}, \mathrm{FC}, \mathrm{KC}, \mathrm{BD}$, and $\mathrm{AM}$ screened titles for relevance and abstracted the data from the eligible full text articles. $\mathrm{HB}, \mathrm{OH}$, and $\mathrm{WA}$ analyzed and interpreted the data. $\mathrm{HB}, \mathrm{OH}, \mathrm{FC}$, and WA drafted the manuscript. $\mathrm{HB}, \mathrm{OH}$, and WA critically revised the manuscript with input from the entire team. All authors have read and approved the final draft.

\section{ACKNOWLEDGMENTS}

We would like to thank all members in the Dr. Abou-Kheir's Laboratory (The WAK Lab) for their help on this work.

\section{REFERENCES}

Aasen, T., Raya, A., Barrero, M. J., Garreta, E., Consiglio, A., Gonzalez, F., et al. (2008). Efficient and rapid generation of induced pluripotent stem cells from human keratinocytes. Nat. Biotechnol. 26, 1276-1284. doi: 10.1038/ nbt. 1503

Abdullah, A. I., Pollock, A., and Sun, T. (2012). The Path from Skin to Brain: generation of functional neurons from fibroblasts. Mol. Neurobiol. 45, 586-595. doi: 10.1007/s12035-012-8277-6

Abel, O., Powell, J. F., Andersen, P. M., and Al-Chalabi, A. (2012). ALSoD: a userfriendly online bioinformatics tool for amyotrophic lateral sclerosis genetics. Hum. Mutat. 33, 1345-1351. doi: 10.1002/humu.22157 
Alzheimer's Association (2010). 2010 Alzheimer's disease facts and figures. Alzheimer's Dementia. 6, 158-194. doi: 10.1016/j.jalz.2010.01.009

Barry, F. P., and Murphy, J. M. (2004). Mesenchymal stem cells: clinical applications and biological characterization. Int. J. Biochem. Cell. Biol. 36, 568-584. doi: 10.1016/j.biocel.2003.11.001

Bregman, B. S., McAtee, M., Dai, H. N., and Kuhn, P. L. (1997). Neurotrophic factors increase axonal growth after spinal cord injury and transplantation in the adult rat. Exp. Neurol. 148, 475-494. doi: 10.1006/exnr.1997.6705

Byers, B., Lee, H.-L., and Pera, R. R. (2012). Modeling Parkinson's disease using induced pluripotent stem cells. Curr. Neurol. Neurosci. Rep. 12, 237-242. doi: 10.1007/s11910-012-0270-y

Cai, J., Yang, M., Poremsky, E., Kidd, S., Schneider, J. S., and Iacovitti, L. (2009). Dopaminergic neurons derived from human induced pluripotent stem cells survive and integrate into 6-OHDA-lesioned rats. Stem Cells Dev. 19, 1017-1023. doi: 10.1089/scd.2009.0319

Camnasio, S., Carri, A. D., Lombardo, A., Grad, I., Mariotti, C., Castucci, A., et al. (2012). The first reported generation of several induced pluripotent stem cell lines from homozygous and heterozygous Huntington's disease patients demonstrates mutation related enhanced lysosomal activity. Neurobiol. Dis. 46, 41-51. doi: 10.1016/j.nbd.2011.12.042

Chambers, S. M., Fasano, C. A., Papapetrou, E. P., Tomishima, M., Sadelain, M., and Studer, L. (2009). Highly efficient neural conversion of human ES and iPS cells by dual inhibition of SMAD signaling. Nat. Biotechnol. 27, 275-280. doi: $10.1038 /$ nbt.1529

Cheah, B. C., Vucic, S., Krishnan, A. V., and Kiernan, M. C. (2010). Riluzole, neuroprotection and amyotrophic lateral sclerosis. Curr. Med. Chem. 17, 1942-1959. doi: 10.2174/092986710791163939

Chestkov, I. V., Vasilieva, E. A., Illarioshkin, S. N., Lagarkova, M. A., and Kiselev, S. L. (2014). Patient-specific induced pluripotent stem cells for SOD1-associated amyotrophic lateral sclerosis pathogenesis studies. Acta Naturae. 6, 54-60.

Chilton, J. K. (2006). Molecular mechanisms of axon guidance. Dev. Biol. 292, 13-24. doi: 10.1016/j.ydbio.2005.12.048

Chung, S., Leung, A., Han, B.-S., Chang, M.-Y., Moon, J.-I., Kim, C.-H., et al. (2009). Wnt1-lmxla forms a novel autoregulatory loop and controls midbrain dopaminergic differentiation synergistically with the SHH-FoxA2 pathway. Cell Stem Cell. 5, 646-658. doi: 10.1016/j.stem.2009.09.015

Cooper, O., Hargus, G., Deleidi, M., Blak, A., Osborn, T., Marlow, E., et al. (2010). Differentiation of human ES and Parkinson's disease iPS cells into ventral midbrain dopaminergic neurons requires a high activity form of SHH, FGF8a and specific regionalization by retinoic acid. Mol. Cell. Neurosci. 45, 258-266. doi: $10.1016 /$ j.mcn.2010.06.017

Correia, A. S., Anisimov, S. V., Li, J.-Y., and Brundin, P. (2005). Stem cell-based therapy for Parkinson's disease. Ann. Med. 37, 487-498. doi: 10.1080/07853890500327967

Cummings, B. J., Uchida, N., Tamaki, S. J., Salazar, D. L., Hooshmand, M., Summers, R., et al. (2005). Human neural stem cells differentiate and promote locomotor recovery in spinal cord-injured mice. Proc. Natl. Acad. Sci. U.S.A. 102, 14069-14074. doi: 10.1073/pnas.0507063102

Devine, M. J., Ryten, M., Vodicka, P., Thomson, A. J., Burdon, T., Houlden, H., et al. (2011). Parkinson's disease induced pluripotent stem cells with triplication of the $\alpha$-synuclein locus. Nat. Commun. 2:440. doi: 10.1038/ncomms1453

Di Giorgio, F. P., Carrasco, M. A., Siao, M. C., Maniatis, T., and Eggan, K. (2007). Non-cell autonomous effect of glia on motor neurons in an embryonic stem cell-based ALS model. Nat. Neurosci. 10, 608-614. doi: 10.1038/nn1885

Dimos, J. T., Rodolfa, K. T., Niakan, K. K., Weisenthal, L. M., Mitsumoto, H., Chung, W., et al. (2008). Induced pluripotent stem cells generated from patients with ALS can be differentiated into motor neurons. Science 321, 1218-1221. doi: 10.1126/science.1158799

Donnelly, C. J., Zhang, P. W., Pham, J. T., Haeusler, A. R., Mistry, N. A., Vidensky, S., et al. (2013). RNA toxicity from the ALS/FTD C9ORF72 expansion is mitigated by antisense intervention. Neuron 80, 415-428. doi: 10.1016/j.neuron.2013.10.015

Donnelly, D. J., and Popovich, P. G. (2008). Inflammation and its role in neuroprotection, axonal regeneration and functional recovery after spinal cord injury. Exp. Neurol. 209, 378-388. doi: 10.1016/j.expneurol.2007.06.009

Doulames, V. M., and Plant, G. W. (2016). Induced pluripotent stem cell therapies for cervical spinal cord injury. Int. J. Mol. Sci. 17:530. doi: $10.3390 / \mathrm{ijms} 17040530$
Duan, L. (2014). Stem cell derived basal forebrain cholinergic neurons from Alzheimer's disease patients are more susceptible to cell death. Mol. Neurodegener. 9:3. doi: 10.1186/1750-1326-9-3

Dunnett, S. B., Carter, R. J., Watts, C., Torres, E. M., Mahal, A., Mangiarini, L., et al. (1998). Striatal transplantation in a transgenic mouse model of Huntington's disease. Exp. Neurol. 154, 31-40. doi: 10.1006/exnr.1998.6926

Egashira, T., Yuasa, S., and Fukuda, K. (2011). Induced pluripotent stem cells in cardiovascular medicine. Stem Cells Int. 2011:348960. doi: $10.4061 / 2011 / 348960$

Evans, M. J., and Kaufman, M. H. (1981). Establishment in culture of pluripotential cells from mouse embryos. Nature 292, 154-156.

Ferri, A. L. M., Lin, W., Mavromatakis, Y. E., Wang, J. C., Sasaki, H., Whitsett, J. A., et al. (2007). Foxa1 and Foxa2 regulate multiple phases of midbrain dopaminergic neuron development in a dosage-dependent manner. Development 134, 2761-2769. doi: 10.1242/dev.000141

Fields, R. D., and Stevens-Graham, B. (2002). New insights into neuron-glia communication. Science 298, 556-562. doi: 10.1126/science.298.5593.556

Fujiwara, N., Shimizu, J., Takai, K., Arimitsu, N., Saito, A., Kono, T., et al. (2013). Restoration of spatial memory dysfunction of human APP transgenic mice by transplantation of neuronal precursors derived from human iPS cells. Neurosci. Lett. 557(pt B), 129-134. doi: 10.1016/j.neulet.2013.10.043

Ganat, Y. M., Calder, E. L., Kriks, S., Nelander, J., Tu, E. Y., Jia, F., et al. (2012). Identification of embryonic stem cell-derived midbrain dopaminergic neurons for engraftment. J. Clin. Invest. 122, 2928-2939. doi: 10.1172/JCI58767

Gasser, T. (2007). Update on the genetics of Parkinson's disease. Mov. Disord. 22, S343-S350. doi: $10.1002 / \mathrm{mds} .21676$

Gil, J. M., and Rego, A. C. (2009). The R6 lines of transgenic mice: a model for screening new therapies for Huntington's disease. Brain Res. Rev. 59, 410-431. doi: 10.1016/j.brainresrev.2008.12.001

Giorgetti, A., Montserrat, N., Aasen, T., Gonzalez, F., Rodríguez-Piz,à, I., Vassena, R., et al. (2009). Generation of induced pluripotent stem cells from human cord blood using OCT4 and SOX2. Cell Stem Cell. 5:353. doi: 10.1016/j.stem.2009.09.008

González, F., Boué, S., and Belmonte, J. C. I. (2011). Methods for making induced pluripotent stem cells: reprogramming a la carte. Nat. Rev. Genet. 12, 231-242. doi: $10.1038 / \mathrm{nrg} 2937$

Grealish, S., Diguet, E., Kirkeby, A., Mattsson, B., Heuer, A., Bramoulle, Y., et al. (2014). Human ESC-Derived Dopamine Neurons Show Similar Preclinical Efficacy and Potency to Fetal Neurons when Grafted in a Rat Model of Parkinson's Disease. Cell Stem Cell. 15, 653-665. doi: 10.1016/j.stem.2014.09.017

Guo, Z., Zhang, L., Wu, Z., Chen, Y., Wang, F., and Chen, G. (2014). In vivo direct reprogramming of reactive glial cells into functional neurons after brain injury and in an Alzheimer's disease model. Cell Stem Cell. 14, 188-202. doi: 10.1016/j.stem.2013.12.001

Hadadeh, O., Barruet, E., Peiretti, F., Verdier, M., Bernot, D., Hadjal, Y., et al. (2012). The plasminogen activation system modulates differently adipogenesis and myogenesis of embryonic stem cells. PLoS ONE 7:e49065. doi: 10.1371/journal.pone.0049065

Hallett, P. J., Deleidi, M., Astradsson, A., Smith, G. A., Cooper, O., Osborn, T. M., et al. (2015). Successful function of autologous iPSC-derived dopamine neurons following transplantation in a non-human primate model of Parkinson's disease. Cell Stem Cell. 16, 269-274. doi: 10.1016/j.stem.2015. 01.018

Han, F., Wang, W., Chen, B., Chen, C., Li, S., Lu, X., et al. (2015). Human induced pluripotent stem cell-derived neurons improve motor asymmetry in a 6-hydroxydopamine-induced rat model of Parkinson's disease. Cytotherapy 17, 665-679. doi: 10.1016/j.jcyt.2015.02.001

Hedges, E. C., Mehler, V. J., and Nishimura, A. L. (2016). The use of stem cells to model amyotrophic lateral sclerosis and frontotemporal dementia: from basic research to regenerative medicine. Stem Cells Int. 2016:9279516. doi: 10.1155/2016/9279516

Heman-Ackah, S. M., Bassett, A. R., and Wood, M. J. A. (2016). Precision modulation of neurodegenerative disease-related gene expression in human iPSC-derived neurons. Sci. Rep. 6:28420. doi: 10.1038/srep28420

Herberts, C. A., Kwa, M. S. G., and Hermsen, H. P. H. (2011). Risk factors in the development of stem cell therapy. J. Transl. Med. 9:1. doi: 10.1186/1479-5876-9-29 
Hochedlinger, K., and Jaenisch, R. (2006). Nuclear reprogramming and pluripotency. Nature 441, 1061-1067. doi: 10.1038/nature04955

Hong, J. Y., Lee, S. H., Lee, S. C., Kim, J.-W., Kim, K.-P., Kim, S. M., et al. (2014). Therapeutic potential of induced neural stem cells for spinal cord injury. J. Biol. Chem. 289, 32512-32525. doi: 10.1074/jbc.M114.588871

Horner, P. J., and Gage, F. H. (2000). Regenerating the damaged central nervous system. Nature 407, 963-970. doi: 10.1038/35039559

Hou, S., and Lu, P. (2016). Direct reprogramming of somatic cells into neural stem cells or neurons for neurological disorders. Neural Regen. Res. 11, 28-31. doi: $10.4103 / 1673-5374.169602$

Howe, S. J., Mansour, M. R., Schwarzwaelder, K., Bartholomae, C., Hubank, M., Kempski, H., et al. (2008). Insertional mutagenesis combined with acquired somatic mutations causes leukemogenesis following gene therapy of SCID-X1 patients. J. Clin. Invest. 118, 3143-3150. doi: 10.1172/jci35798

Hu, Z., Pu, J., Jiang, H. Zhong, P., Qiu, J., Li, F., et al. (2015). Generation of naivetropic induced pluripotent stem cells from Parkinson's disease patients for high-efficiency genetic manipulation and disease modeling. Stem Cells Dev. 24, 2591-2604. doi: 10.1089/scd.2015.0079

Huangfu, D., Maehr, R., Guo, W., Eijkelenboom, A., Snitow, M., Chen, A. E., et al. (2008). Induction of pluripotent stem cells by defined factors is greatly improved by small-molecule compounds. Nat. Biotechnol. 26, 795-797. doi: $10.1038 / n b t 1418$

Ikegami, T., Nakamura, M., Yamane, J., Katoh, H., Okada, S., Iwanami, A., et al. (2005). Chondroitinase ABC combined with neural stem/progenitor cell transplantation enhances graft cell migration and outgrowth of growthassociated protein-43-positive fibers after rat spinal cord injury. Eur. J. Neurosci. 22, 3036-3046. doi: 10.1111/j.1460-9568.2005.04492.x

Israel, M. A., Yuan, S. H., Bardy, C., Reyna, S. M., Mu, Y., Herrera, C., et al. (2012). Probing sporadic and familial Alzheimer/'s disease using induced pluripotent stem cells. Nature 482, 216-220. doi: 10.1038/nature10821

Jones, L. L., Oudega, M., Bunge, M. B., and Tuszynski, M. H. (2001). Neurotrophic factors, cellular bridges and gene therapy for spinal cord injury. J. Physiol. 533, 83-89. doi: 10.1111/j.1469-7793.2001.0083b.x

Kang, X., Xu, H., Teng, S., Zhang, X., Deng, Z., Zhou, L., et al. (2014). Dopamine release from transplanted neural stem cells in Parkinsonian rat striatum in vivo. Proc. Natl. Acad. Sci. U.S.A. 111, 15804-15809. doi: 10.1073/pnas.14084 84111

Karch, C. M., and Goate, A. M. (2015). Alzheimer's disease risk genes and mechanisms of disease pathogenesis. Biol. Psychiatry 77, 43-51. doi: 10.1016/j.biopsych.2014.05.006

Kaye, J. A., and Finkbeiner, S. (2013). Modeling Huntington's Disease with induced pluripotent stem cells. Mol. Cell. Neurosci. 56, 50-64. doi: 10.1016/j.mcn.2013.02.005

Keller, G. M. (1995). In vitro differentiation of embryonic stem cells. Curr. Opin. Cell Biol. 7, 862-869. doi: 10.1016/0955-0674(95)80071-9

Khodosevich, K., and Monyer, H. (2011). Signaling in migrating neurons: from molecules to networks. Front. Neurosci. 5:28. doi: 10.3389/fnins.2011.00028

Kim, S. M., Flaßkamp, H., Hermann, A., Araúzo-Bravo, M. J., Lee, S. C., Lee, S. H., et al. (2014). Direct conversion of mouse fibroblasts into induced neural stem cells. Nat. Protoc. 9, 871-881. doi: 10.1038/nprot.2014.056

Kime, C., Mandegar, M. A., Srivastava, D., Yamanaka, S., Conklin, B. R., and Rand, T. A. (2016). Efficient CRISPR/Cas9-Based genome engineering in human pluripotent stem cells. Curr. Protoc. Hum. Genet 88, Unit 21.24. doi: 10.1002/0471142905.hg2104s88

Kittappa, R., Chang, W. W., Awatramani, R. B., and McKay, R. D. G. (2007). The foxa2 gene controls the birth and spontaneous degeneration of dopamine neurons in old age. PLoS Biol. 5:e325. doi: 10.1371/journal.pbio.0050325

Lancaster, M. A., and Knoblich, J. A. (2014). Generation of cerebral organoids from human pluripotent stem cells. Nat. Protoc. 9, 2329-2340. doi: $10.1038 /$ nprot.2014.158

Lau, S., Rylander Ottosson, D., Jakobsson, J., and Parmar, M. (2014). Direct neural conversion from human fibroblasts using self-regulating and nonintegrating viral vectors. Cell Rep. 9, 1673-1680. doi: 10.1016/j.celrep.2014.11.017

Li, J. Y., Popovic, N., and Brundin, P. (2005). The use of the R6 transgenic mouse models of Huntington's disease in attempts to develop novel therapeutic strategies. NeuroRx 2, 447-464. doi: 10.1602/neurorx.2.3.447

Li, X.-J., Zhang, X., Johnson, M. A., Wang, Z.-B., LaVaute, T., and Zhang, S.C. (2009). Coordination of sonic hedgehog and Wnt signaling determines ventral and dorsal telencephalic neuron types from human embryonic stem cells. Development 136, 4055-4063. doi: 10.1242/dev.036624

Li, Y., Balasubramanian, U., Cohen, D., Zhang, P.-W., Mosmiller, E., Sattler, R., et al. (2015). A comprehensive library of familial human amyotrophic lateral sclerosis induced pluripotent stem cells. PLOS ONE 10:e0118266. doi: 10.1371/journal.pone.0118266

Lindborg, B. A., Brekke, J. H., Vegoe, A. L., Ulrich, C. B., Haider, K. T., Subramaniam, S., et al. (2016). Rapid Induction of cerebral organoids from human induced pluripotent stem cells using a chemically defined hydrogel and defined cell culture medium. Stem Cells Transl. Med. 5, 970-979. doi: $10.5966 / \mathrm{sctm} .2015-0305$

Livesey, M. R. (2016). Maturation and electrophysiological properties of human pluripotent stem cell-derived oligodendrocytes. Stem Cells. 34, 1040-1053. doi: $10.1002 /$ stem.2273

Lo, B., and Parham, L. (2009). Ethical issues in stem cell research. Endocr. Rev. 30, 204-213. doi: 10.1210/er.2008-0031

Lopez-Leon, M., Reggiani, P. C., Herenu, C. B., and Goya, R. G. (2014). Regenerative medicine for the aging brain. Enliven. J. Stem Cell Res. Regen. Med. $1,1-9$.

Mallanna, S. K., and Rizzino, A. (2010). Emerging roles of microRNAs in the control of embryonic stem cells and the generation of induced pluripotent stem cells. Dev. Biol. 344, 16-25. doi: 10.1016/j.ydbio.2010.05.014

Mandegar, M. A., Huebsch, N., Frolov, E. B., Shin, E., Truong, A., Olvera, M. P., et al. (2016). CRISPR Interference Efficiently Induces Specific and Reversible Gene Silencing in Human iPSCs. Cell Stem Cell. 18, 541-553. doi: 10.1016/j.stem.2016.01.022

Mangiarini, L., Sathasivam, K., Seller, M., Cozens, B., Harper, A., Hetherington, C., et al. (1996). Exon 1 of the HD gene with an expanded CAG repeat is sufficient to cause a progressive neurological phenotype in transgenic mice. Cell 87, 493-506. doi: 10.1016/S0092-8674(00)81369-0

Martin, G. R. (1981). Isolation of a pluripotent cell line from early mouse embryos cultured in medium conditioned by teratocarcinoma stem cells. Proc. Natl. Acad. Sci. U.S.A. 78, 7634-7638.

Miura, K., Okada, Y., Aoi, T., Okada, A., Takahashi, K., Okita, K., et al. (2009). Variation in the safety of induced pluripotent stem cell lines. Nat. Biotechnol. 27, 743-745. doi: $10.1038 /$ nbt.1554

Morizane, A., Kikuchi, T., Nishimura, K., and Takahashi, J. (2011). Small-molecule inhibitors of bone morphogenic protein and activin/nodal signals promote highly efficient neural induction from human pluripotent stem cells. J. Neurosci. Res. 89, 117-126. doi: 10.1002/jnr.22547

Mungenast, A. E., Siegert, S., and Tsai, L. H. (2016). Modeling Alzheimer's disease with human induced pluripotent stem (iPS) cells. Mol. Cell. Neurosci. 73, 13-31. doi: $10.1016 /$ j.men.2015.11.010

Nagai, M., Re, D. B., Nagata, T., Chalazonitis, A., Jessell, T. M., Wichterle, H., et al. (2007). Astrocytes expressing ALS-linked mutated SOD1 release factors selectively toxic to motor neurons. Nat. Neurosci. 10, 615-622. doi: $10.1038 / \mathrm{nn} 1876$

Nakamura, M., and Okano, H. (2013). Cell transplantation therapies for spinal cord injury focusing on induced pluripotent stem cells. Cell Res. 23, 70-80. doi: 10.1038/cr.2012.171

Nekrasov, E. D., Vigont, V. A., Klyushnikov, S. A., Lebedeva, O. S., Vassina, E. M., Bogomazova, A. N., et al. (2016). Manifestation of Huntington's disease pathology in human induced pluripotent stem cell-derived neurons. Mol. Neurodegener. 11:27. doi: 10.1186/s13024-016-0092-5

Nicholas, C. R., Chen, J., Tang, Y., Southwell, D. G., Chalmers, N., Vogt, D., et al. (2013). Functional maturation of hPSC-derived forebrain interneurons requires an extended timeline and mimics human neural development. Cell Stem Cell 12, 573-586. doi: 10.1016/j.stem.2013.04.005

Nieweg, K., Andreyeva, A., van Stegen, B., Tanriöver, G., and Gottmann, K. (2015). Alzheimer's disease-related amyloid- $\beta$ induces synaptotoxicity in human iPS cell-derived neurons. Cell Death Dis. 6:e1709. doi: 10.1038/cddis.2015.72

Niwa, H. (2007). How is pluripotency determined and maintained? Development 134, 635-646. doi: 10.1242/dev.02787

Nori, S., Okada, Y., Nishimura, S., Sasaki, T., Itakura, G., Kobayashi, Y., et al. (2015). Long-term safety issues of iPSC-based cell therapy in a spinal cord injury model: oncogenic transformation with epithelial-mesenchymal transition. Stem Cell Reports 4, 360-373. doi: 10.1016/j.stemcr.2015. 01.006 
Okano, H., Nakamura, M., Yoshida, K., Okada, Y., Tsuji, O., Nori, S., et al. (2013). Steps toward safe cell therapy using induced pluripotent stem cells. Circ. Res. 112, 523-533. doi: 10.1161/circresaha.111.256149

Oki, K., Tatarishvili, J., Wood, J., Koch, P., Wattananit, S., Mine, Y., et al. (2012). Human-induced pluripotent stem cells form functional neurons and improve recovery after grafting in stroke-damaged brain. Stem Cells 30, 1120-1133. doi: $10.1002 /$ stem. 1104

Okita, K., Ichisaka, T., and Yamanaka, S. (2007). Generation of germlinecompetent induced pluripotent stem cells. Nature 448, 313-317. doi: $10.1038 /$ nature05934

Pagliuca, F. W., Millman, J. R., Gürtler, M., Segel, M., Van Dervort, A., Ryu, J. H., et al. (2014). Generation of functional human pancreatic $\beta$ cells in vitro. Cell 159, 428-439. doi: 10.1016/j.cell.2014.09.040

Pajer, K., Nemes, C., Berzsenyi, S., Kovács, K. A., Pirity, M. K., Pajenda, G., et al. (2015). Grafted murine induced pluripotent stem cells prevent death of injured rat motoneurons otherwise destined to die. Exp. Neurol. 269, 188-201. doi: 10.1016/j.expneurol.2015.03.031

Paquet, D., Kwart, D., Chen, A., Sproul, A., Jacob, S., Teo, S., et al. (2016). Efficient introduction of specific homozygous and heterozygous mutations using CRISPR/Cas9. Nature 533, 125-129. doi: 10.1038/nature 17664

Park, I.-H., Arora, N., Huo, H., Maherali, N., Ahfeldt, T., Shimamura, A., et al. (2008a). Disease-specific induced pluripotent stem cells. Cell 134, 877-886. doi: 10.1016/j.cell.2008.07.041

Park, I.-H., Zhao, R., West, J. A., Yabuuchi, A., Huo, H., Ince, T. A., et al. (2008b). Reprogramming of human somatic cells to pluripotency with defined factors. Nature 451, 141-146. doi: 10.1038/nature06534

Parr, A. M., Kulbatski, I., Zahir, T., Wang, X., Yue, C., Keating, A., et al. (2008). Transplanted adult spinal cord-derived neural stem/progenitor cells promote early functional recovery after rat spinal cord injury. Neuroscience 155, 760-770. doi: 10.1016/j.neuroscience.2008.05.042

Pei, D., Xu, J., Zhuang, Q., Tse, H.-F., and Esteban, M. A. (2010). "Induced pluripotent stem cell technology in regenerative medicine and biology," in Bioreactor Systems for Tissue Engineering II, Vol. 123., eds C. Kasper, M. Van Griensven, and R. Pörtner (New York: Springer), 127-141.

Plant, G. W., Bates, M. L., and Bunge, M. B. (2001). Inhibitory proteoglycan immunoreactivity is higher at the caudal than the rostral Schwann cell graft-transected spinal cord interface. Mol. Cell. Neurosci. 17, 471-487. doi: $10.1006 /$ mcne.2000.0948

Qiang, L., Fujita, R., Yamashita, T., Angulo, S., Rhinn, H., Rhee, D., et al. (2011). Directed conversion of Alzheimer's disease patient skin fibroblasts into functional neurons. Cell 146, 359-371. doi: 10.1016/j.cell.2011. 07.007

Quadrato, G., Brown, J., and Arlotta, P. (2016). The promises and challenges of human brain organoids as models of neuropsychiatric disease. Nat. Med. 22, 1220-1228. doi: 10.1038/nm.4214

Raab, S., Klingenstein, M., Liebau, S., and Linta, L. (2014). A comparative view on human somatic cell sources for iPSC generation. Stem Cells Int. 2014:12. doi: $10.1155 / 2014 / 768391$

Raisman, G. (2001). Olfactory ensheathing cells-another miracle cure for spinal cord injury? Nat. Rev. Neurosci. 2, 369-375. doi: 10.1038/35072576

Ramer, L. M., Au, E., Richter, M. W., Liu, J., Tetzlaff, W., and Roskams, A. J. (2004). Peripheral olfactory ensheathing cells reduce scar and cavity formation and promote regeneration after spinal cord injury. J. Comp. Neurol. 473, 1-15. doi: 10.1002/cne.20049

Rhee, Y. H., Ko, J. Y., Chang, M. Y., Yi, S. H., Kim, D., Kim, C. H., et al. (2011). Protein-based human iPS cells efficiently generate functional dopamine neurons and can treat a rat model of Parkinson disease. J. Clin. Invest. 121, 2326-2335. doi: 10.1172/jci45794

Roessler, R., Smallwood, S. A., Veenvliet, J. V., Pechlivanoglou, P., Peng, S. P., Chakrabarty, K., et al. (2014). Detailed analysis of the genetic and epigenetic signatures of iPSC-derived mesodiencephalic dopaminergic neurons. Stem Cell Reports 2, 520-533. doi: 10.1016/j.stemcr.2014.03.001

Romanyuk, N., Amemori, T., Turnovcova, K., Prochazka, P., Onteniente, B., Sykova, E., et al. (2015). Beneficial effect of human induced pluripotent stem cell-derived neural precursors in spinal cord injury repair. Cell Transplant. 24, 1781-1797. doi: 10.3727/096368914X684042
Rubio, A., Luoni, M., Giannelli, S. G., Radice, I., Iannielli, A., Cancellieri, C., et al. (2016). Rapid and efficient CRISPR/Cas9 gene inactivation in human neurons during human pluripotent stem cell differentiation and direct reprogramming. Sci. Rep. 6:37540. doi: 10.1038/srep37540

Ryan, S. D., Dolatabadi, N., Chan, S. F., Zhang, X., Akhtar, M. W., Parker, J., et al. (2013). Isogenic human iPSC Parkinson's model shows nitrosative stressinduced dysfunction in MEF2-PGC1 $\alpha$ transcription. Cell 155, 1351-1364. doi: 10.1016/j.cell.2013.11.009

Sances, S., Bruijn, L., Chandran, S., Eggan, K., Ho, R., Klim, J., et al. (2016). Modeling ALS using motor neurons derived from human induced pluripotent stem cells. Nat. Neurosci. 19, 542-553. doi: 10.1038/nn.4273

Sánchez-Danés, A., Richaud-Patin, Y., Carballo-Carbajal, I., Jiménez-Delgado, S., Caig, C., Mora, S., et al. (2012). Disease-specific phenotypes in dopamine neurons from human iPS-based models of genetic and sporadic Parkinson's disease. EMBO Mol. Med. 4, 380-395. doi: 10.1002/emmm.201200215

Sareen, D., O’Rourke, J. G., Meera, P., Muhammad, A., Grant, S., Simpkinson, M., et al. (2013). Targeting RNA foci in iPSC-derived motor neurons from ALS patients with C9ORF72 repeat expansion. Sci. Transl. Med. 5:208ra149. doi: 10.1126/scitranslmed.3007529

Scheiffele, P. (2003). Cell-cell signaling during synapse formation in the CNS. Annu. Rev. Neurosci. 26, 485-508. doi: 10.1146/annurev.neuro.26.043002.094940

Schulz, J. B. (2008). Update on the pathogenesis of Parkinson's disease. J. Neurol. 255 (Suppl. 5), 3-7. doi: 10.1007/s00415-008-5011-4

Serio, A., Bilican, B., Barmada, S. J., Ando, D. M., Zhao, C., Siller, R., et al. (2013). Astrocyte pathology and the absence of non-cell autonomy in an induced pluripotent stem cell model of TDP-43 proteinopathy. Proc. Natl. Acad. Sci. U.S.A. 110, 4697-4702. doi: 10.1073/pnas.1300398110

Serretti, A., Olgiati, P., and De Ronchi, D. (2007). Genetics of Alzheimer's disease. A rapidly evolving field. J. Alzheimers Dis. 12, 73-92.

Soldner, F., Hockemeyer, D., Beard, C., Gao, Q., Bell, G. W., Cook, E. G., et al. (2009). Parkinson's disease patient-derived induced pluripotent stem cells free of viral reprogramming factors. Cell 136, 964-977. doi: 10.1016/j.cell.2009.02.013

Sonntag, K. C., Pruszak, J., Yoshizaki, T., van Arensbergen, J., Sanchez-Pernaute, R., and Isacson, O. (2007). Enhanced yield of neuroepithelial precursors and midbrain-like dopaminergic neurons from human embryonic stem cells using the bone morphogenic protein antagonist noggin. Stem Cells 25, 411-418. doi: 10.1634/stemcells.2006-0380

Sproul, A. A. (2015). Being human: the role of pluripotent stem cells in regenerative medicine and humanizing Alzheimer's disease models. Mol. Aspects Med. 43, 54-65. doi: 10.1016/j.mam.2015.06.007

Su, R. J., Neises, A., and Zhang, X. B. (2016). Generation of iPS cells from human peripheral blood mononuclear cells using episomal vectors. Methods Mol. Biol. 1357, 57-69. doi: 10.1007/7651_2014_139

Surmacz, B., Noisa, P., Risner-Janiczek, J. R., Hui, K., Ungless, M., Cui, W., et al. (2012). DLK1 promotes neurogenesis of human and mouse pluripotent stem cell-derived neural progenitors via modulating Notch and BMP signalling. Stem Cell Rev. 8, 459-471. doi: 10.1007/s12015-011-9298-7

Takahashi, K., Tanabe, K., Ohnuki, M., Narita, M., Ichisaka, T., Tomoda, K., et al. (2007). Induction of pluripotent stem cells from adult human fibroblasts by defined factors. Cell 131, 861-872. doi: 10.1016/j.cell.2007.11.019

Takahashi, K., and Yamanaka, S. (2006). Induction of pluripotent stem cells from mouse embryonic and adult fibroblast cultures by defined factors. Cell 126, 663-676. doi: 10.1016/j.cell.2006.07.024

The International Stem Cell Consortium Initiative, Akopian, V., Andrews, P. W., Beil, S., Benvenisty, N., Brehm, J., et al. (2010). Comparison of defined culture systems for feeder cell free propagation of human embryonic stem cells. In Vitro Cell. Dev. Biol. Anim. 46, 247-258. doi: 10.1007/s11626-010-9297-z

Thomson, J. A., Itskovitz-Eldor, J., Shapiro, S. S., Waknitz, M. A., Swiergiel, J. J., Marshall, V. S., et al. (1998). Embryonic stem cell lines derived from human blastocysts. Science (New York, NY). 282, 1145-1147. doi: 10.1126/science.282.5391.1145

Tousley, A., and Kegel-Gleason, K. B. (2016). Induced pluripotent stem cells in Huntington's disease research: progress and opportunity. J. Huntingtons. Dis. 5, 99-131. doi: 10.3233/jhd-160199

Trounson, A., and DeWitt, N. D. (2016). Pluripotent stem cells progressing to the clinic. Nat. Rev. Mol. Cell Biol. 17, 194-200. doi: 10.1038/nrm.2016.10 
Tsubooka, N., Ichisaka, T., Okita, K., Takahashi, K., Nakagawa, M., and Yamanaka, S. (2009). Roles of Sall4 in the generation of pluripotent stem cells from blastocysts and fibroblasts. Genes Cells 14, 683-694. doi: 10.1111/j.1365-2443.2009.01301.x

Tsuji, O., Miura, K., Okada, Y., Fujiyoshi, K., Mukaino, M., Nagoshi, N., et al. (2010). Therapeutic potential of appropriately evaluated safe-induced pluripotent stem cells for spinal cord injury. Proc. Natl. Acad. Sci. U.S.A. 107, 12704-12709. doi: 10.1073/pnas.0910106107

Unternaehrer, J. J., and Daley, G. Q. (2011). Induced pluripotent stem cells for modelling human diseases. Philos. Trans. R. Soc. Lond. B. Biol. Sci. 366, 2274-2285. doi: 10.1098/rstb.2011.0017

Wang, Y., Baskerville, S., Shenoy, A., Babiarz, J. E., Baehner, L., and Blelloch, R. (2008). Embryonic stem cell-specific microRNAs regulate the G1-S transition and promote rapid proliferation. Nat. Genet. 40, 1478-1483. doi: $10.1038 / \mathrm{ng} .250$

Wenker, S. D., Casalía, M., Candedo, V. C., Casabona, J. C., and Pitossi, F. J. (2015). Cell reprogramming and neuronal differentiation applied to neurodegenerative diseases: focus on Parkinson's disease. FEBS Lett. 589, 3396-3406. doi: 10.1016/j.febslet.2015.07.023

Wernig, M., Meissner, A., Foreman, R., Brambrink, T., Ku, M., Hochedlinger, $\mathrm{K}$., et al. (2007). In vitro reprogramming of fibroblasts into a pluripotent ES-cell-like state. Nature 448, 318-324. doi: 10.1038/nature05944

Wernig, M., Zhao, J. P., Pruszak, J., Hedlund, E., Fu, D., Soldner, F., et al. (2008). Neurons derived from reprogrammed fibroblasts functionally integrate into the fetal brain and improve symptoms of rats with Parkinson's disease. Proc. Natl. Acad. Sci. U.S.A. 105, 5856-5861. doi: 10.1073/pnas.0801677105

Yagi, T., Ito, D., Okada, Y., Akamatsu, W., Nihei, Y., Yoshizaki, T., et al. (2011). Modeling familial Alzheimer's disease with induced pluripotent stem cells. Hum. Mol. Genet. 20, 4530-4539. doi: 10.1093/hmg/ddr394

Yahata, N., Asai, M., Kitaoka, S., Takahashi, K., Asaka, I., Hioki, H., et al. (2011). Anti-A $\beta$ drug screening platform using human iPS cell-derived neurons for the treatment of Alzheimer's disease. PLoS ONE 6:e25788 doi: 10.1371/journal.pone.0025788

Yang, C. R., and Yu, R. K. (2009). Intracerebral transplantation of neural stem cells combined with trehalose ingestion alleviates pathology in a mouse model of Huntington's disease. J. Neurosci. Res. 87, 26-33. doi: 10.1002/jnr.21817

Yang, J., Li, S., He, X.-B., Cheng, C., and Le, W. (2016). Induced pluripotent stem cells in Alzheimer's disease: applications for disease modeling and cell-replacement therapy. Mol. Neurodegener. 11:39. doi: 10.1186/s13024-016-0106-3

Zaehres, H., Kogler, G., Arauzo-Bravo, M. J., Bleidissel, M., Santourlidis, S., Weinhold, S., et al. (2010). Induction of pluripotency in human cord blood unrestricted somatic stem cells. Exp. Hematol. 38, 809-818, 818.e801-802. doi: 10.1016/j.exphem.2010.05.009

Zhang, N., An, M. C., Montoro, D., and Ellerby, L. M. (2010). Characterization of human Huntington's disease cell model from induced pluripotent stem cells. PLoS Curr. 2:RRN1193. doi: 10.1371/currents.RRN1193

Zhao, Y., Yin, X., Qin, H., Zhu, F., Liu, H., Yang, W., et al. (2008). Two supporting factors greatly improve the efficiency of human iPSC generation. Cell Stem Cell. 3, 475-479. doi: 10.1016/j.stem.2008.10.002

Conflict of Interest Statement: The authors declare that the research was conducted in the absence of any commercial or financial relationships that could be construed as a potential conflict of interest.

Copyright (c) 2017 Bahmad, Hadadeh, Chamaa, Cheaito, Darwish, Makkawi and Abou-Kheir. This is an open-access article distributed under the terms of the Creative Commons Attribution License (CC BY). The use, distribution or reproduction in other forums is permitted, provided the original author(s) or licensor are credited and that the original publication in this journal is cited, in accordance with accepted academic practice. No use, distribution or reproduction is permitted which does not comply with these terms. 